\title{
ACTRIS ACSM intercomparison - Part 1: Reproducibility of concentration and fragment results from 13 individual Quadrupole Aerosol Chemical Speciation Monitors (Q-ACSM) and consistency with co-located instruments
}

\author{
V. Crenn ${ }^{1}$, J. Sciare ${ }^{1,2}$, P. L. Croteau ${ }^{3}$, S. Verlhac ${ }^{4}$, R. Fröhlich ${ }^{5}$, C. A. Belis ${ }^{6}$, W. Aas ${ }^{7}$, M. Äijälä ${ }^{8}$, A. Alastuey ${ }^{9}$, \\ B. Artiñano ${ }^{10}$, D. Baisnée ${ }^{1}$, N. Bonnaire ${ }^{1}$, M. Bressi ${ }^{6}$, M. Canagaratna ${ }^{3}$, F. Canonaco ${ }^{5}$, C. Carbone ${ }^{11}$, F. Cavalli $^{6}$, \\ E. Coz $^{10}$, M. J. Cubison ${ }^{12}$, J. K. Esser-Giett ${ }^{13}$, D. C. Green ${ }^{14}$, V. Gros ${ }^{1}$, L. Heikkinen ${ }^{8}$, H. Herrmann ${ }^{15}$, C. Lunder ${ }^{7}$, \\ M. C. Minguillón ${ }^{9}$, G. Močnik ${ }^{16}$, C. D. O'Dowd ${ }^{17}$, J. Ovadnevaite ${ }^{17}$, J.-E. Petit ${ }^{1,4}$, E. Petralia ${ }^{18}$, L. Poulain ${ }^{15}$, \\ M. Priestman ${ }^{14}$, V. Riffault ${ }^{19}$, A. Ripoll ${ }^{9}$, R. Sarda-Estève ${ }^{1}$, J. G. Slowik ${ }^{6}$, A. Setyan ${ }^{19}$, A. Wiedensohler ${ }^{15}$, \\ U. Baltensperger ${ }^{5}$, A. S. H. Prévôt ${ }^{5}$, J. T. Jayne ${ }^{3}$, and O. Favez ${ }^{4}$ \\ ${ }^{1}$ Laboratoire des Sciences du Climat et de l'Environnement, LSCE, CNRS-CEA-UVSQ, Gif-sur-Yvette, France \\ ${ }^{2}$ The Cyprus Institute, Environment Energy and Water Research Center, Nicosia, Cyprus \\ ${ }^{3}$ Aerodyne Research, Inc., Billerica, Massachusetts, USA \\ ${ }^{4}$ INERIS, Verneuil-en-Halatte, France \\ ${ }^{5}$ Laboratory of Atmospheric Chemistry, Paul Scherrer Institute, Villigen PSI, Switzerland \\ ${ }^{6}$ European Commission, Joint Research Centre (JRC), Institute for Environment and Sustainability (IES), \\ Air and Climate Unit, Ispra (VA), Italy \\ ${ }^{7}$ NILU - Norwegian Institute for Air Research, Kjeller, Norway \\ ${ }^{8}$ Department of Physics, University of Helsinki, Helsinki, Finland \\ ${ }^{9}$ Institute of Environmental Assessment and Water Research (IDAEA-CSIC), Barcelona, Spain \\ ${ }^{10}$ Centre for Energy, Environment and Technology Research (CIEMAT), Department of the Environment, Madrid, Spain \\ ${ }^{11}$ Proambiente S.c.r.l., CNR Research Area, Bologna, Italy \\ ${ }^{12}$ TOFWERK AG, Thun, Switzerland \\ ${ }^{13}$ Deutscher Wetterdienst, Meteorologisches Observatorium Hohenpeißenberg, Hohenpeißenberg, Germany \\ ${ }^{14}$ Environmental Research Group, MRC-HPA Centre for Environment and Health, King's College London, London, UK \\ ${ }^{15}$ Leibniz Institute for Tropospheric Research, Leipzig, Germany \\ ${ }^{16}$ Aerosol d.o.o., Ljubljana, Slovenia \\ ${ }^{17}$ School of Physics and Centre for Climate and Air Pollution Studies, Ryan Institute, National University of Ireland Galway, \\ University Road, Galway, Ireland \\ ${ }^{18}$ ENEA-National Agency for New Technologies, Energy and Sustainable Economic Development, Bologna, Italy \\ ${ }^{19}$ Ecole Nationale Supérieure des Mines de Douai, Département Sciences de l'Atmosphère et Génie \\ de l'Environnement, Douai, France
}

Correspondence to: J. Sciare (j.sciare@cyi.ac.cy)

Received: 7 May 2015 - Published in Atmos. Meas. Tech. Discuss.: 14 July 2015

Revised: 5 November 2015 - Accepted: 14 November 2015 - Published: 2 December 2015

Published by Copernicus Publications on behalf of the European Geosciences Union. 
Abstract. As part of the European ACTRIS project, the first large Quadrupole Aerosol Chemical Speciation Monitor (QACSM) intercomparison study was conducted in the region of Paris for 3 weeks during the late-fall-early-winter period (November-December 2013). The first week was dedicated to the tuning and calibration of each instrument, whereas the second and third were dedicated to side-by-side comparison in ambient conditions with co-located instruments providing independent information on submicron aerosol optical, physical, and chemical properties. Near real-time measurements of the major chemical species (organic matter, sulfate, nitrate, ammonium, and chloride) in the non-refractory submicron aerosols (NR-PM $)_{1}$ were obtained here from 13 QACSM. The results show that these instruments can produce highly comparable and robust measurements of the NR-PM total mass and its major components. Taking the median of the 13 Q-ACSM as a reference for this study, strong correlations $\left(r^{2}>0.9\right)$ were observed systematically for each individual Q-ACSM across all chemical families except for chloride for which three Q-ACSMs showing weak correlations partly due to the very low concentrations during the study. Reproducibility expanded uncertainties of Q-ACSM concentration measurements were determined using appropriate methodologies defined by the International Standard Organization (ISO 17025, 1999) and were found to be 9 ,

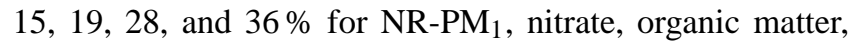
sulfate, and ammonium, respectively. However, discrepancies were observed in the relative concentrations of the constituent mass fragments for each chemical component. In particular, significant differences were observed for the organic fragment at mass-to-charge ratio 44 , which is a key parameter describing the oxidation state of organic aerosol. Following this first major intercomparison exercise of a large number of Q-ACSMs, detailed intercomparison results are presented, along with a discussion of some recommendations about best calibration practices, standardized data processing, and data treatment.

\section{Introduction}

Anthropogenic aerosols are ubiquitous pollutants in ambient air and play a significant role in the radiative balance of the Earth's atmosphere through its direct or indirect effects (Forster et al., 2007). Moreover, these aerosols, especially the fine fraction with aerodynamic diameters less than $2.5 \mu \mathrm{m}$ $\left(\mathrm{PM}_{2.5}\right)$, have been recognized as having adverse effects on human health due to their ability to penetrate deeper into the respiratory system (WHO, 2012) and due to the presence of toxic compounds in their composition.

Over the past few decades, worldwide efforts have been made to better characterize these aerosols and their various impacts through coordinated networking activities. Such initiatives allow providing reliable and comprehensive observa- tions of the chemical composition and selected physical and optical characteristics of the atmosphere in order to provide the scientific community with the means to predict future atmospheric states and to give recommendations for the building of environmental policies.

At the European level, the ACTRIS project (Aerosols, Clouds, and Trace gases Research InfraStructure Network; http://www.actris.net/) aims to improve and harmonize observations of the in situ aerosol properties (chemical composition, optical, cloud condensation nuclei and size distribution) through a network of ground-based stations equipped with advanced atmospheric probing instrumentation for aerosols, clouds, and short-lived gas-phase species.

In recent years, the Q-ACSM (Aerodyne Res. Inc, ARI, Billerica, MA.; $\mathrm{Ng}$ et al., 2011a) has been operated at most of the European ACTRIS ground-based stations due to its capability to provide near real-time measurements of the major chemical components of non-refractory submicron particles $\left(\mathrm{NR}-\mathrm{PM}_{1}\right)$ and to allow for source apportionment of organic aerosols. The Q-ACSM was built on the same operating principles as the Aerodyne Aerosol Mass Spectrometer (AMS, Canagaratna et al., 2007) with the main differences being that the latter is equipped with a particle beam chopper that allows for the determination of the size distribution of submicron aerosol and its major components and that the Q-ACSM is based on simpler but more robust technologies. In particular, the Q-ACSM uses a lower performance quadrupole mass spectrometer, resulting in less sensitivity and mass-to-charge $(\mathrm{m} / \mathrm{z})$ resolution but with the advantage of being cheaper and more suited for long-term unattended operation. A new version of ACSM, equipped with a time-of-flight (ToF) mass spectrometer, has been developed recently. This ToF-ACSM provides higher sensitivity, mass resolution and mass range compared to the Q-ACSM (Fröhlich et al., 2013).

Q-ACSM measurements have been performed at various places around the world after the first reported deployment of this instrument in New York, USA (Ng et al., 2011a). For instance, Q-ACSM were already used in China for the characterization of summer and spring organic and inorganic aerosols in Beijing (Sun et al., 2012; Jiang et al., 2015, respectively), as well as in urban Nanjing and in the Yangtze River delta region during summer and autumn harvest seasons (Zhang et al., 2015), in Tijuana, Mexico, from local and southern California sources during the CalMex campaign (Takahama et al., 2013), in Santiago de Chile, Chile (Carbone et al., 2013), in Atlanta (Budisulistiorini et al., 2013, 2014, 2015a), in Hawaii (Kroll et al., 2015), in Look Rock, USA (Budisulistiorini et al., 2015a, b), in the eastern Mediterranean during summertime to study the processing of biomass burning aerosols (Bougiatioti et al., 2014), and in the region of Paris, France, to investigate wintertime pollution events (Petit et al., 2014). Several long-term Q-ACSM measurement data sets (> 10 months) are also now available for sites in the central USA (e.g., at the Atmospheric Radiation Measurement (ARM) program's Southern Great Plains 
(SGP) site (Parworth et al., 2015)), in the southeastern United States (e.g., Atlanta, Georgia and Look Rock, Tennessee (Budisulistiorini et al., 2015a)) and in Europe as part of the ACTRIS program (e.g., for Zurich, Switzerland (Canonaco et al., 2013), both the remote and regional background Spanish sites of Montsec and Montseny (Ripoll et al., 2015; Minguillón et al., 2015, respectively), and the Paris area, France (Petit et al., 2015). Intercomparison studies of aerosol measurements have been regularly performed to validate the different European data sets obtained within the EMEP (European Monitoring and Evaluation Programme, http://www. emep.int/) and/or ACTRIS networks (see for instance Baumgardner et al., 2012; Laborde et al., 2012; Petzold et al., 2013, for aerosol optical properties; Wiedensohler et al., 2012, for Scanning Mobility Particle Sizer (SMPS) intercomparison; and Cavalli et al., 2013; Panteliadis et al., 2015; Yttri et al., 2015, for filter-based measurements of elemental/organic carbon and anhydride sugars). However, there is still no intercomparison study available to assess atmospheric concentration and source apportionment results from the Q-ACSM network in Europe. Budisulistiorini et al. (2014) have recently compared the measurements from two Q-ACSMs in Atlanta, Georgia. The results were very encouraging showing very good agreement among data sets with $r^{2}$ above 0.8 for the major species, except for chlorides $\left(r^{2}=0.21\right)$, which were observed in low atmospheric concentrations close to or below the detection limit of both Q-ACSMs. In order to validate both Q-ACSM data sets, species concentrations were then compared to other co-located instruments (e.g., particle-intoliquid-sampler coupled to ion chromatography, PILS-IC, and Thermo Scientific Sulfate Particulate Analyzer), highlighting satisfactory correlations which are consistent with previous results obtained by $\mathrm{Ng}$ et al. (2011a) and Sun et al. (2012) for 8 weeks of continuous measurements from co-located QACSM and High-Resolution Time-of-Flight AMS (HR-ToFAMS) during its very first deployment in Queens, New York. Fröhlich et al. (2013) also showed quantitative agreement with slopes close to unity for all NR-PM 1 species between Q-ACSM, ToF-ACSM and a Compact Time-of-Flight AMS (C-ToF-AMS) measurements.

In the present study, 13 individual Q-ACSM were deployed at the same location during a 2-week field campaign. The objective of this paper is to assess, over a large number of instruments, the overall uncertainties of Q-ACSM measurements (concentrations and mass spectral fragmentation patterns) under optimized operating conditions (Q-ACSM settings, tunings, and calibration procedures) and favorable ambient conditions (in the vicinity of a large urban area) providing important variability of each individual chemical component measured by Q-ACSM. The reproducibility of QACSM measurements is investigated here with respect to a reference (defined as the median of the 13 intercompared QACSM). The consistency of these measurements with filterbased chemical analyses and other online co-located instruments (including a ToF-ACSM, a High Resolution ToF-AMS
(HR-ToF-AMS), a PILS-IC and automatic monitors of the aerosol physical properties) is also discussed in the present paper. Based on the experience gained through this first intercomparison study, some recommendations are then provided regarding the operation of Q-ACSM instruments within the European ACTRIS network and the need to perform similar large intercomparison studies on a regular basis. Two companion papers (Fröhlich et al., 2015; Belis et al., 2015) focus more specifically on the results of source apportionment of organic aerosol (OA) derived from the Q- and ToF-ACSM and HR-ToF-AMS measurement.

\section{Calibration facilities, intercomparison experimental strategy, and meteorological overview}

\subsection{The Aerosol Chemical Monitor Calibration Center (ACMCC)}

The ACSM intercomparison study took place at the newly established Aerosol Chemical Monitor Calibration Center (ACMCC), which is a component of the ACTRIS European Center for Aerosol Calibration. It benefits from the co-located long-term in situ aerosol observations performed at the French SIRTA atmospheric station (Site Instrumental de Recherche par Télédétection Atmosphérique; http://sirta. ipsl.fr/; Haeffelin et al., 2005), part of the ACTRIS atmospheric network. The ACMCC and in situ (reactive gases and aerosol) observations of SIRTA are co-located at LSCE (Laboratoire des Sciences, du Climat et de 1'Environnement), located about $25 \mathrm{~km}$ southwest of Paris $\left(48.71^{\circ} \mathrm{N}, 2.15^{\circ} \mathrm{E}\right.$, $150 \mathrm{~m}$ above sea level; Petit et al., 2014). The SIRTA station is considered to be a site representative of regional background pollution in the region of Paris and has already been referenced in the past as one of the three stationary measurement sites of the EU-FP6-MEGAPOLI project (Megacities: Emissions, urban, regional, and Global Atmospheric POLlution and climate effects, and Integrated tools for assessment and mitigation (Beekmann et al., 2015; Crippa et al., 2013a, b, c; Freutel et al., 2013a, b; Healy et al., 2013; von der Weiden-Reinmüller et al., 2014; Zhang et al., 2013).

\subsection{Intercomparison experimental strategy}

The study was conducted during 3 weeks (from 10 November to 3 December 2013). Fifteen laboratories located in 10 European countries have participated in this intercomparison exercise and brought their ACSM/AMS to ACMCC. The participants and the associated ACTRIS stations where ACSMs have been commonly deployed are listed in Table 1 . The first week was dedicated to the installation of the aerosol mass spectrometers, their connection to air inlets (see Sect. 3.1), their upgrades (software version), their tuning and calibration (see Sect. 3.1.1). Technical support was provided by the manufacturer (ARI) during this first week of tuning and cal- 
Table 1. List of Q-ACSM instruments, laboratories and corresponding ACTRIS stations. The order of Q-ACSM in this table purposely does not coincide with the order no. 1-13 used in the text to avoid an unintentional "rating" of individual instruments.

\begin{tabular}{lllll}
\hline Q-ACSM S/N & Q-ACSM type & Station ID of Q-ACSM location & Laboratory & Country \\
\hline A140-110 & Q-ACSM & Montseny & IDAEA-CSIC & Spain \\
A140-144 & Q-ACSM & Birkenes & NILU & Norway \\
A140-134 & Q-ACSM & Hohenpeissenberg & DWD & Germany \\
A140-142 & Q-ACSM & Cape Corsica & LSCE & France \\
A140-104 & Q-ACSM & Hyytiälä & University of Helsinki & Finland \\
A140-153 & Q-ACSM & Madrid & CIEMAT & Spain \\
A140-143 & Q-ACSM & Melpitz & TROPOS & Germany \\
A140-145 & Q-ACSM & Cabauw & PSI & Switzerland \\
A140-152 & Q-ACSM & Bologna & ISAC-CNR & Italy \\
A140-133 & Q-ACSM & Mace Head & NUIG & Ireland \\
A140-151 & Q-ACSM & Bologna and Ispra & ENEA and EC-JRC & Italy and EU \\
A140-113 & Q-ACSM & Sirta & LSCE & France \\
A140-156 & Q-ACSM & North Kensington & King's College & UK \\
\hline
\end{tabular}

ibration. All the laboratories attended in this first week and undertook to the calibration of their own instrument.

The second and third weeks (from 15 November, 18:00 UTC, to 2 December, 00:00 UTC) were dedicated to side-by-side measurements in ambient air. Here, the ACSMs (including the ToF-ACSM) were randomly gathered into four groups. Q-ACSMs no. 1, 3, 6, and 11 were in Group A; QACSMs no. 7, 9, 10, and 13 in Group B; Q-ACSMs no. 2, 5, 8 and the ToF-ACSM in Group C, while Q-ACSMs no. 4 and 12 were in Group D. Each group had its own sampling line consisting of a $3 \mathrm{~m}$ stainless steel tube of $1 / 2^{\prime \prime}$ outer diameter (o.d.) and a common cut-off inlet (URG Cyclone 2000-30EH, Chapel Hill, NC, USA), located at $\sim 6 \mathrm{~m}$ above the ground. As each ACSM subsampled a flow of $3 \mathrm{~L} \mathrm{~min}^{-1}$ from the general inlets, the total flow passing through these inlets was of $12 \mathrm{~L} \mathrm{~min}^{-1}$ and the cyclone cut-off was approximately of $2 \mu \mathrm{m}$ (rather than the $2.5 \mu \mathrm{m}$ cut-off obtained when using this kind of cyclone at $16.7 \mathrm{~L} \mathrm{~min}^{-1}$ ). Each ACSM was then equipped with its own drying system, corresponding to the individual device commonly used when operating within the ACTRIS program. All these dryers were based on Nafion membranes and no influence of the drying system diversity could be observed on the results obtained from the different instruments.

A final calibration was performed at the end of the intercomparison study before shipping back each instrument.

\subsection{Meteorological conditions}

The temporal variability of meteorological parameters is presented in Fig. 1. The average temperature during the intercomparison study was $3.8 \pm 1.7^{\circ} \mathrm{C}$ ranging from -0.3 to $9.6^{\circ} \mathrm{C}$. During the ambient comparison period (17 November-2 December), only a few rainfall events occurred (total of $11.4 \mathrm{~mm}$ of precipitation during the whole period), in association with clean air masses from marine

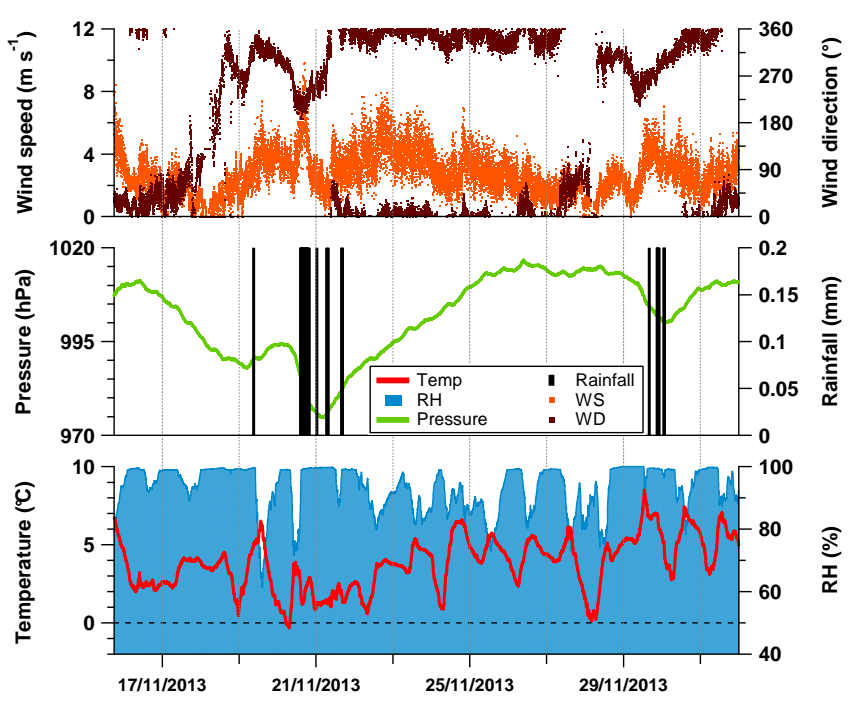

Figure 1. Time series of meteorological parameters during the intercomparison study.

origin. The remaining was characterized by quite stable atmospheric conditions with air masses mainly coming from the north (wind directions covering $240-60^{\circ} \mathrm{N}$ ) favorable to the development of PM pollution episodes over the region of Paris (Crippa et al., 2013c; Petit et al., 2014), thus providing ideal conditions with changing local and regional-scale pollution sources during the intercomparison study.

\section{Instrumentation and calibration}

After a brief description of the Q-ACSM measurement principle, the different calibration procedures applied for the present study are presented below. The co-located aerosol monitors providing information on physical/optical/chemical properties of submicron particles are also presented in this 
section. All the instruments were placed in an air conditioned room maintained at approximately $18^{\circ} \mathrm{C}$ during the whole campaign.

\subsection{Aerosol Chemical Speciation Monitor (Q-ACSM)}

The Q-ACSM measures mass concentrations of nonrefractory submicron aerosol components (i.e., organic matter, nitrate, sulfate, ammonium and chloride, noted hereafter $\mathrm{OM}, \mathrm{NO}_{3}, \mathrm{SO}_{4}, \mathrm{NH}_{4}$, and $\mathrm{Cl}$, respectively). An exhaustive description of the instrument is available in $\mathrm{Ng}$ et al. (2011a) and information about differences between Q-ACSM and AMS is given in Budisulistiorini et al. (2014). Briefly, compared to AMS, Q-ACSM systems use a lower performance mass spectrometer resulting in reduced sensitivity providing time resolution of about 30 min for typical urban aerosol loadings, and do not provide size-resolved measurements. $\mathrm{PM}_{2.5}$ aerosol particles are typically sampled and dried at $3 \mathrm{~L} \mathrm{~min}^{-1}$ (regulated with a mass flowmeter), and then subsampled isokinetically at $\sim 85 \mathrm{~mL} \mathrm{~min}^{-1}$ into a high vacuum system through a $100 \mu \mathrm{m}$ diameter critical orifice mounted at the inlet of an aerodynamic lens focusing submicron particles with vacuum aerodynamic diameter $\left(D_{\mathrm{va}}\right)$ of around 40 $1000 \mathrm{~nm}$ (Liu et al., 2007). The gas from the particle beam is separated by using differential pumping. The narrow particle beam (approximately $1 \mathrm{~mm}$ diameter) is then impacted onto a resistively $600^{\circ} \mathrm{C}$-heated inverted-cone semiporous tungsten vaporizer, mounted inside the ionization chamber, where non-refractory components are flash-vaporized and quasiinstantaneously ionized by electron impact $(70 \mathrm{eV})$. Resulting positive ions are finally detected following their massto-charge $(\mathrm{m} / \mathrm{z})$ ratios by a Prisma quadrupole mass spectrometer (Pfeiffer Vacuum, model QMS220), which provides chemical composition information by reporting aerosol mass spectra $(12<m / z<148$ amus). A small effusive source of naphthalene (having $m / z$ at 128 notably) located in the detection region is used as a reference for $m / z$ and ion transmission calibrations as described in Sect. 3.1.1. During data acquisition, a three-way automated valve mounted upstream of the inlet switches alternatively between a filter position (air without any particle) and sample position (air with particles). Subtraction of the filter mass spectrum from the sample mass spectrum provides information about the particulate chemical composition which is then averaged over a selected number of scans. Obtained spectra are then used to extract the chemically speciated aerosol mass loadings by using the same fragmentation table as described by Allan et al. (2004) and then by applying calibration values and correction algorithms (see Sects. 3.1.1 and 3.1.2). This fragmentation table was recently updated (Canagaratna et al., 2015) for AMS data treatment, but the latter optimized fragmentation table was not used in the present study, in order to be consistent with the actual ACTRIS program recommendations.

\subsubsection{Calibration protocols}

The aerodynamic lens system of each instrument was aligned according to the protocols described in AMS and ACSM previous publications (Jayne et al., 2000; Ng et al., 2011a) to ensure that the particle beam was well centered on the particle vaporizer and all voltages were tuned for best instrument performance and data quality before calibrating.

Several further operations were performed on each ACSM before calibration and consisted in harmonizing software versions (data acquisition and processing), detector gain, and data acquisition parameters (scan rate, number, time duration and $m / z$ coverage for each scan). In order to have homogeneous data processing between ACSMs, all the instruments used the latest data acquisition software (DAQ) version provided by ARI (v1.4.4.5) to calculate aerosol mass concentrations.

\section{$m / z$ calibration}

Q-ACSMs were operated from mass-to-charge $(\mathrm{m} / z)$ 12-148 with a scan speed of $200 \mathrm{~ms} \mathrm{amu}^{-1}$ and 28 cycles of ambient and filter scans. The sampling time of all measurements presented here is expressed in coordinated universal time (UTC). The mass-to-charge calibration of the quadrupole was performed using two calibration points, the $\mathrm{N}_{2}$ peak corresponding to the air-beam $(\mathrm{AB})$ signal used to normalize the measurements with respect to drifts in instrument measurement sensitivity and sampling flow rate, and the internal naphthalene $\left(\mathrm{C}_{10} \mathrm{H}_{8}^{+}\right)$standard peak until they are centered at their nominal mass values $(\mathrm{m} / z 28$ and 128 , respectively) during $m / z$ scans. These signals are also used to determine the relative ion transmission (RIT) efficiency as shown in Sect. 3.1.3. The acquisition parameters have been monitored for each Q-ACSM during the whole sampling period to ensure stable conditions during data acquisition. The average values are given in the Supplement Table S1.

\section{(Relative) ion efficiency calibration}

ACSM and AMS species mass concentrations are expressed in nitrate equivalent mass, based on the determination of the effective nitrate response factor and ionization efficiency $\left(\mathrm{RF}_{\mathrm{NO}_{3}}\right.$ and $\mathrm{IE}_{\mathrm{NO}_{3}}$ respectively). The $\mathrm{IE}_{\mathrm{NO}_{3}}$ calibration procedure was applied to all ACSM/AMS systems using a unique calibration setup presented in Fig. 2, thus helping to reduce systematic biases between instruments. Calibrations were performed with ammonium nitrate $\left(\mathrm{NH}_{4} \mathrm{NO}_{3}\right)$ aerosols, which were atomized (TSI aerosol generator, Model 3076) from an aqueous solution of concentration $5 \mathrm{mM}$ in ultrapure water. To ensure that atomized particles are well-dried during the calibrations, a Nafion dryer (Thermo Scientific Particulate Dryer) was coupled with a silica-gel diffusion dryer (TSI model 3062) directly placed after the atomizer. In order to minimize the quantity of humid air flowing through the 
Table 2. Calibrated values of the Q-ACSM response function (RF) in $\mathrm{A} /\left(\mu \mathrm{g} \mathrm{m}^{-3}\right)$ and RIE values used in the present study.

\begin{tabular}{crrrrrr}
\hline ACSM no. & $\mathrm{RF}_{\mathrm{NO}_{3}}\left(10^{-11}\right)$ & $\mathrm{RIE}_{\mathrm{NH}_{4}}$ & $\mathrm{RIE}_{\mathrm{NO}_{3}}$ & $\mathrm{RIE}_{4}$ & $\mathrm{RIE}$ & $\mathrm{RIE}_{\mathrm{Org}}$ \\
\hline 1 & 5.26 & 3.37 & 1.1 & 1.2 & 1.3 & 1.4 \\
2 & 2.80 & 14.72 & 1.1 & 1.2 & 1.3 & 1.4 \\
3 & 3.06 & 5.48 & 1.1 & 1.2 & 1.3 & 1.4 \\
4 & 3.69 & 8.98 & 1.1 & 1.2 & 1.3 & 1.4 \\
5 & 2.98 & 3.42 & 1.1 & 1.2 & 1.3 & 1.4 \\
6 & 3.13 & 4.72 & 1.1 & 1.2 & 1.3 & 1.4 \\
7 & 5.47 & 7.24 & 1.1 & 1.2 & 1.3 & 1.4 \\
8 & 2.34 & 6.45 & 1.1 & 1.2 & 1.3 & 1.4 \\
9 & 2.74 & 3.56 & 1.1 & 1.2 & 1.3 & 1.4 \\
10 & 3.97 & 7.79 & 1.1 & 1.2 & 1.3 & 1.4 \\
11 & 3.02 & 3.17 & 1.1 & 1.2 & 1.3 & 1.4 \\
12 & 4.43 & 3.83 & 1.1 & 1.2 & 1.3 & 1.4 \\
13 & 3.31 & 9.36 & 1.1 & 1.2 & 1.3 & 1.4 \\
\hline
\end{tabular}

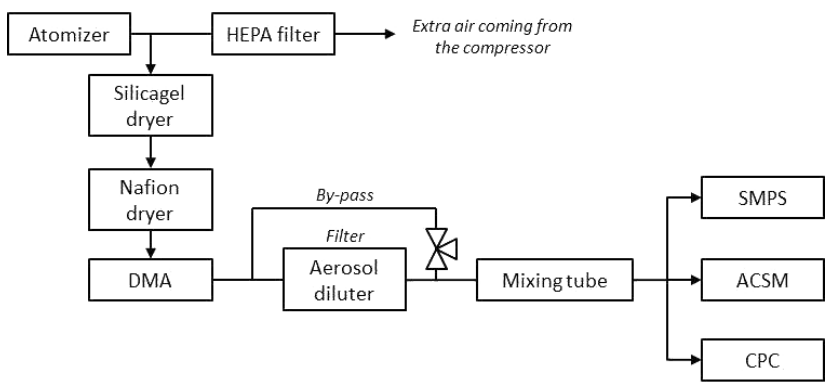

Figure 2. Aerosol mass spectrometers (i.e., ACSMs and HR-ToFAMS) calibration setup. The relative humidity (RH) was monitored downstream of the Nafion dryer.

two dryers, a tee was added (upstream the dryers) to release the excess air flowing through the atomizer.

The relative humidity $(\mathrm{RH})$ was monitored downstream of the dryers during the calibrations to check that the generated particles remained dry. RH values were systematically below $10 \%(6 \%<\mathrm{RH}<10 \%)$ for all the ACSM/AMS calibrations. Particles were then selected at $300 \mathrm{~nm}$ mobility diameter by the means of a Differential Mobility Analyzer (DMA) (TSI Electrostatic classifier, Model 3081). The DMA impactor was also cleaned before each Q-ACSM calibration and a factor of 10 was applied between the sheath and sample flow rates. The DMA size calibration was successfully checked by injection of mono-dispersed polystyrene latex (PSL) spheres of 200, 350, and $491 \mathrm{~nm}$ (Duke Scientific). An aerosol dilution device was placed after the DMA (and before a mixing tube) in order to change the mass loading of the monodispersed $\mathrm{NH}_{4} \mathrm{NO}_{3}$ particles in the range $0-15 \mu \mathrm{g} \mathrm{m}^{-3}$. This system was then connected to both a Condensation Particle Counter (CPC, TSI model 3025) and an aerosol mass spectrometer inlet (one at a time). Both the DMA and CPC performances and calibration were tested 1 month prior to the intercomparison study at the World Calibration
Centre for Aerosol Physics (WCCAP, TROPOS, Leipzig, Germany; http://www.wmo-gaw-wcc-aerosol-physics.org/). The performance of the calibration system to produce monodispersed $\mathrm{NH}_{4} \mathrm{NO}_{3}$ was also tested using a Scanning Mobility Particle Sizing (SMPS, Grimm, Model 5.416) running in scanning mode. This control was performed before and after the calibration of each Q-ACSM. The SMPS instrument used here to control the mono-dispersed $\mathrm{NH}_{4} \mathrm{NO}_{3}$ was also successfully checked at the WCCAP the month before the intercomparison study. Each ACSM/AMS was stabilized for at least $24 \mathrm{~h}$ before calibrations were performed.

\section{(Relative) ion efficiency calibration results}

The $\mathrm{RF}_{\mathrm{NO}_{3}}$ and RIE values used for each Q-ACSM instrument within this study are reported in Table 2. As shown in the Supplement (Table S1), the Q-ACSM particle vaporization and ionization parameters are not exactly the same between Q-ACSMs resulting in differences in absolute and relative ionization efficiencies.

All the Q-ACSMs were calibrated $\left(\mathrm{IE}_{\mathrm{NO}_{3}}\right)$ before and after their side-by-side intercomparison in ambient conditions using the calibration system described above. Almost 2 working days were necessary to perform all of these calibrations. Using the SMPS to monitor the size distribution of particles generated by the $\mathrm{IE}_{\mathrm{NO}_{3}}$ calibration system, it was found that the modal mean diameter of mono-dispersed $\mathrm{NH}_{4} \mathrm{NO}_{3}$ particles delivered by the DMA was slightly lower than the expected value of $300 \mathrm{~nm}$ (ranging from 278 to $296 \mathrm{~nm}$ for the calibration of the 13 Q-ACSMs). Once converted into mass concentrations, this slight shift in the diameter of mono-dispersed $\mathrm{NH}_{4} \mathrm{NO}_{3}$ could change $\mathrm{IE}_{\mathrm{NO}_{3}}$ by up to $25 \%$. Based on these observations, $\left(\mathrm{IE}_{\mathrm{NO}_{3}}\right)$ values for each Q-ACSM were corrected by taking account the true mean diameter of particles. Since the size distribution of the monodispersed $\mathrm{NH}_{4} \mathrm{NO}_{3}$ was only checked for the second calibration, it was decided to keep this calibration as the reference 
for the data treatment. Accordingly, the $\mathrm{RIE}_{\mathrm{NH}_{4}}$ value measured for each Q-ACSM during the second calibration phase was used to calculate $\mathrm{NH}_{4}$ mass concentrations.

A unique $\mathrm{RIE}_{\mathrm{SO}_{4}}$ value of 1.2 (corresponding to the default value commonly used for AMS measurements, Canagaratna et al., 2007) was chosen in our study for all QACSMs instead of taking into account the results delivered by the $\mathrm{RIE}_{\mathrm{SO}_{4}}$ calibration performed at the beginning. This decision was taken considering both the lack of historical determination of $\mathrm{RIESO}_{4}$ for some of the Q-ACSMs used here and the uncertainties linked to the size-selected aerosols generated by the DMA, as size distribution of mono-dispersed $\left(\mathrm{NH}_{4}\right)_{2} \mathrm{SO}_{4}$ was not checked in the present study. Note that this choice of a 1.2 $\mathrm{RIE}_{\mathrm{SO}_{4}}$ value is in good agreement with the only data reported so far for long-term measurements at ACTRIS stations and obtained from calibration using ammonium sulfate generated particles (Petit et al., 2015; Ripoll et al., 2015; Minguillón et al., 2015). However, other recent studies illustrate the need to use instrument dependent $\mathrm{RIE}_{\mathrm{SO}_{4}}$ for Q-ACSM measurements (e.g., Budisulistiorini et al., 2014), so that the actual $\mathrm{RIE}_{\mathrm{SO}_{4}}$ value might be significantly different from 1.2 for some of the Q-ACSMs used here. The impacts of applying individual $\mathrm{RIE}_{\mathrm{SO}_{4}}$ values to calculate $\mathrm{SO}_{4}$ mass concentrations is detailed in the Supplement (see Sect. S2), indicating however a higher dispersion of $\mathrm{SO}_{4}$ measurements than when using a unique $\mathrm{RIE}_{\mathrm{SO}_{4}}$ default value. Future ACSM intercomparison studies should address this issue more carefully.

\section{Ambient Q-ACSM data processing}

A composition-dependent collection efficiency (CE) correction was applied to all ACSM/AMS data according to the procedure described by Middlebrook et al. (2012). Such correction was motivated by the high ammonium nitrate mass fraction (ANMF) measured in the aerosol mass composition during the ambient intercomparison (see Sect. 5.1.1). The time series of CE is given in the Supplement (see Sect. S3). The RH in the sampling line was not identified as a key factor influencing CE because of the use of individual dryers at the entrance of each ACSM.

A short air beam (AB, the integrated signal at $m / z 28$, corresponding to $\mathrm{N}_{2}^{+}$) period set as close as possible to $10^{-7} \times \mathrm{A}$ to which the detector gain is optimized and corresponding to a stable IE/AB signal was defined as the reference period for each Q-ACSM to minimize the impact of the constant decrease of $\mathrm{AB}$ over time and the influence of small $\mathrm{AB}$ fluctuations owing predominantly to changes in system sensitivity, flow/pressure changes.

Due to the use of a lower grade of quadrupole mass spectrometer, the RIT of Q-ACSM depends on $m / z$. Therefore a correction must be applied to compensate the rapid decrease of ion transmission at high $m / z$. An internal naphthalene standard, continuously emitted, is used to correct the ion transmission by following the signal at $\mathrm{m} / \mathrm{z}$ 128, which

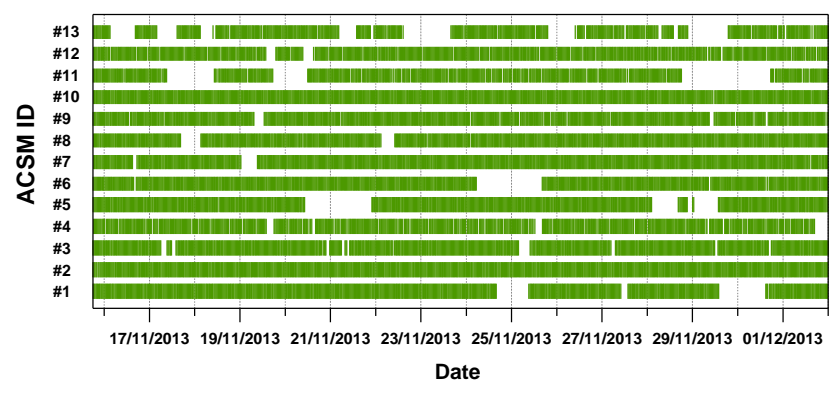

Figure 3. Q-ACSMs temporal coverage during the intercomparison study.

allows the determination of the type of correction to be applied: exponential, linear, power or quadratic. In this study, power law and exponential RIT fitting curves were used depending on Q-ACSMs. Sensitivity tests performed showed that the slopes of mass concentrations obtained between the two different fitting curves are very close to 1 . Based on these results, the type of RIT correction was not considered to be a major issue in the calculation of mass concentrations and, for that reason, was not taken into account in Sect. 5.1.1 for the Q-ACSM measurement uncertainties.

After data processing, some measurement periods were excluded from the data analysis due to operational and maintenance issues (e.g., critical orifice clogging, Prisma disconnection, low AB signal, calibration and voltage tuning periods, unexplained concentration spikes, unexpected laptop shutdowns, and sudden modification of Q-ACSM parameters such as heater temperature jumps above $10 \%$ ). The temporal coverage of the ambient intercomparison, presented in Fig. 3 (from 16 November to 1 December) was $91.2 \%$ on average, varying from $70.2 \%$ (Q-ACSM no. 13) to $100 \%$ (Q-ACSM no. 2). A time-base of $30 \mathrm{~min}(N=780)$ was taken for directly plotting correlations between ACSMs with a mathematical interpolation function. The latter function allows assigning concentration values obtained from each Q-ACSM within a common fixed timeframe, which was needed here since the original Q-ACSM measurement period is not exactly constant over time. This interpolation function, developed by ARI, was based on the linear weighting of two subsequent data points by the durations between each of these points and the corresponding point within the common timeframe.

\subsection{Co-located aerosol instruments}

Consistency of Q-ACSM measurements was investigated here by comparison with additional (co-located) aerosol instruments deployed during the intercomparison exercise and listed in Table 3. More specifically, NR-PM 1 from Q-ACSM were added to equivalent black carbon (EBC) concentrations from an Aethalometer and compared with $\mathrm{PM}_{1}$ either measured by a TEOM-FDMS or estimated using particle number 
Table 3. List of additional instruments deployed during the intercomparison study.

\begin{tabular}{|c|c|c|}
\hline \multicolumn{3}{|c|}{ Aerosol measurements } \\
\hline Instrument & Parameter & Time resolution \\
\hline HR-ToF-AMS & $\begin{array}{l}\text { NR-PM } \mathrm{PM}_{1} \text { component mass concentrations } \\
\left(\mathrm{OM}, \mathrm{NO}_{3}, \mathrm{SO}_{4}, \mathrm{NH}_{4}, \mathrm{Cl}\right) \text { and size distribution }\end{array}$ & $5 \mathrm{~min}$ \\
\hline PILS-IC & $\mathrm{PM}_{1}$ water-soluble $\mathrm{NO}_{3}, \mathrm{SO}_{4}, \mathrm{Cl}, \mathrm{MSA}$, Oxalate & $20 \mathrm{~min}$ \\
\hline 2 Nephelometers $1-\lambda$ & Light scattering coefficients of $\mathrm{PM}_{1}$ & $5 \mathrm{~min}$ \\
\hline Aethalometer $7-\lambda$ & Equivalent black carbon $(\mathrm{EBC})$ in $\mathrm{PM}_{1}$ & $1 \mathrm{~min}$ \\
\hline TEOM-FDMS & $\mathrm{PM}_{1}$ mass concentration & $15 \mathrm{~min}$ \\
\hline SMPS & Particle number size distribution & $15 \mathrm{~min}$ \\
\hline OPC & Particle number size distribution & $1 \mathrm{~min}$ \\
\hline OCEC Analyzer & $\mathrm{OC}, \mathrm{EC}$ & $2 \mathrm{~h}$ \\
\hline Low-volume sampler & Major anions and cations in $\mathrm{PM}_{2.5}$ & $6 \mathrm{~h}$ \\
\hline
\end{tabular}

size distribution (SMPS) and optical (nephelometer) measurements. Each Q-ACSM chemical component was compared either with on-line (PILS-IC and OCEC Sunset Field instruments) or off-line (filter sampling) measurements. A brief description is provided thereafter for each of these instruments.

Aethalometer-Equivalent black carbon (EBC) mass concentrations in $\mathrm{PM}_{1}$ were measured every $1 \mathrm{~min}$ by a 7 wavelength $(370,470,520,590,660,880$, and $950 \mathrm{~nm})$ Aethalometer (Magee Scientific, AE-33 Model) at a flow rate of $5 \mathrm{~L} \mathrm{~min}^{-1}$. Based on the Dual-spot Technology ${ }^{\circledR}$ (Drinovec et al., 2014), the AE33 presents a new real-time loading effect compensation algorithm based on a dual-spot measurement of optical absorption leading to accurate EBC mass concentration.

Nephelometer-Two integrating single-wavelength (525 and $450 \mathrm{~nm}$ ) nephelometers (Ecotech, Model M9003) were running in parallel to measure continuously ( 5 min time resolution) the dry light scattering coefficient $\left(\sigma_{\mathrm{sp}}\right)$ of $\mathbf{P M}_{1}$. The RH was kept below $40 \%$ inside the two nephelometers with a Nafion dryer (Permapure). Both instruments were checked at the WCCAP intercomparison in March 2013.

SMPS - The particle number size distribution (from 10.25 to $1094 \mathrm{~nm}$ in 89 channels) was determined by a Scanning Mobility Particle Sizer (SMPS, Grimm, Model 5.416) measuring every $15 \mathrm{~min}$. The SMPS was equipped with a Nafion dryer (Thermo Scientific) and a TSP (total suspended particulates) inlet.

PILS-IC-A Particle-into-Liquid Sampler (PILS; Orsini et al., 2003) was coupled with an Ion Chromatograph (IC, Dionex, Model ICS-1100) for the determination of the major water-soluble $\mathrm{PM}_{1}$ inorganic anions. More details on the settings of this PILS-IC instrument are available in Sciare et al. (2011). Five selected major anions $\left(\mathrm{NO}_{3}^{-}, \mathrm{SO}_{4}^{2-}, \mathrm{Cl}^{-}\right.$, Methanesulfonate, Oxalate) were analyzed every $20 \mathrm{~min}$. Calibrations were performed for concentrations ranging from 2 to $1400 \mathrm{ppb}$, using NIST Standard Reference Material for nitrate, sulfate and chloride (SRM no. 723d, 682, and 999b respectively).

OCEC Sunset Field instrument-A semi-continuous OCEC Sunset Field analyzer (Sunset Laboratory Inc., USA) was used to measure thermo-optically the concentrations of organic carbon (OC) and elemental carbon (EC) in $\mathrm{PM}_{2.5}$ every $2 \mathrm{~h}$, using the NIOSH (National Institute for Occupational Safety and Health) thermal protocol (Bae et al., 2004). A volatile organic compound (VOC) denuder (Sunset Laboratory Inc., USA) was installed upstream the analyzer.

TEOM-FDMS - Submicron particle mass concentrations $\left(\mathrm{PM}_{1}\right)$ were continuously measured (every $\left.15 \mathrm{~min}\right)$ by a Tapered Element Oscillating Microbalance (TEOM, Rupprecht and Pataschnik, Model 1400) operating at a temperature of $30^{\circ} \mathrm{C}$ and equipped with a Filter Dynamic Measurement System (FDMS, Model 8500) keeping the sample RH below $25 \%$, as described by Grover et al. (2005).

HR-ToF-AMS-The measurement principle of this aerosol mass spectrometer is available in DeCarlo et al. (2006), and a complete description of its operation and calibration during the present intercomparison exercise is given by Fröhlich et al. (2015). Particles were sampled through an individual $\mathrm{PM}_{2.5}$ cut-off inlet, and AMS mass concentrations were determined every $5 \mathrm{~min}$.

ToF-ACSM - The measurement principle of this recently developed ACSM is available in Fröhlich et al. (2013), and a complete description of its operation and calibration during the present intercomparison exercise is given by Fröhlich et al. (2015). Particles were sampled through a cut-off inlet shared with three Q-ACSMs (see Sect. 2.2), and ToF-ACSM mass concentrations were determined every $10 \mathrm{~min}$.

Low-volume sampler-6h $\mathrm{PM}_{2.5}$ samples were collected on $47 \mathrm{~mm}$ diameter Teflon filters (Millipore ${ }^{\circledR}$ FALP04700 Fluoropore $^{\mathrm{TM}}$ PTFE Membrane Filter, Hydrophobic Plain White, $1 \mu \mathrm{m}$, Merck) using a low-volume sampler (Partisol Plus, Thermo Environment) at a flow rate of $16.7 \mathrm{~L} \mathrm{~min}^{-1}$, and water-soluble inorganic ion analysis were conducted as detailed in Sciare et al. (2008). 


\section{Statistical analysis: definition of the $Z$ score value and uncertainty calculations}

The reproducibility of Q-ACSM measurements $\left(\mathrm{NR}-\mathrm{PM}_{1}\right.$, $\mathrm{OM}, \mathrm{NO}_{3}, \mathrm{SO}_{4}$, and $\mathrm{NH}_{4}$ ) was addressed here using relative deviation to the mean (RDM) and $Z$ score analysis following appropriate standards defined by the International Standard Organization (ISO).

In the following, scatter plots correlations are characterized using the determination coefficient $\left(r^{2}\right)$.

The RDM corresponds to the effective difference from the mean value of two measurements. In the present case, it was chosen to compare data obtained from a given instrument (referred as $i$ ) to data corresponding to the median values of the 13 Q-ACSM measurements (referred as $m$ ):

$\operatorname{RDM}(m, i)=\frac{\left(X_{\mathrm{m}}-X_{\mathrm{i}}\right)}{X_{\mathrm{m}}}$,

where $X_{\mathrm{m}}$ corresponds to the median value of the $13 \mathrm{Q}$ ACSM measurements, and $X_{\mathrm{i}}$ represents the value of a given instrument (Q-ACSM ${ }_{\mathrm{i}}$ ).

The $Z$ score statistical approach evaluates whether the deviations of Q-ACSMs from a reference value fall within a given criterion in order to highlight any bias or influencing factor on the Q-ACSM measurements. The $Z$ score indicator represents a performance criteria provided to each Q-ACSM and yields the relative deviation among Q-ACSMs with respect to a reference or assigned value (here the robust average of Q-ACSM median results). The present choice of the robust average for the reference is motivated here by the lack of a reference method for online measurements of $\mathrm{OM}, \mathrm{NO}_{3}$, $\mathrm{SO}_{4}$ and $\mathrm{NH}_{4}$ in submicron aerosols. The $Z$ score values reported here are those calculated from the measured data (not the interpolated ones).

More precisely, the $Z$ score performance test was conducted for each Q-ACSM species according to ISO 13528 (2005):

$Z_{\mathrm{i}}=\frac{\overline{x_{\mathrm{i}}}-X^{*}}{\sigma_{\mathrm{p}}}$,

where $\overline{x_{\mathrm{i}}}$ is the average concentration of the considered species retrieved from the $\mathrm{Q}-\mathrm{ACSM}_{\mathrm{i}}, X^{*}$, and $\sigma_{\mathrm{p}}$ correspond to the assigned average (robust average) and the standard deviation of all Q-ACSM values used for proficiency testing (calculated using a robust analysis iterative algorithm and given in supporting material), respectively.

Each Q-ACSM performance was then assessed as a function of the calculated $Z$ score values as follows (and adapted from Thompson et al., 2006):

1. absolute $Z$ score values $(|Z|)$ greater than 3 are considered to be unsatisfactory values;

2. $2<|Z| \leq 3$ are considered to be questionable values causing a warning signal;

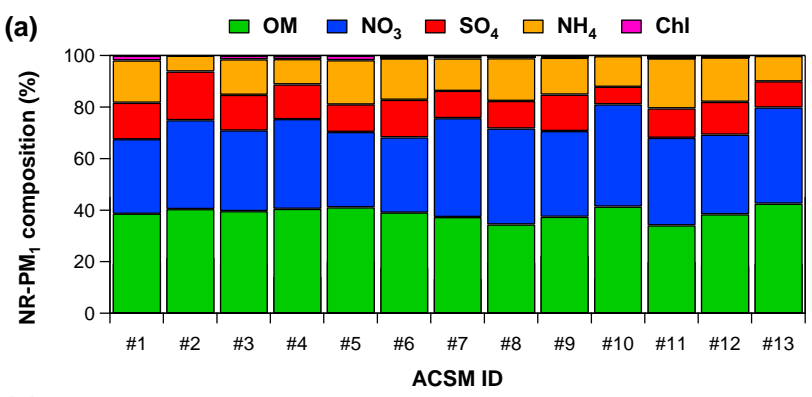

(b)
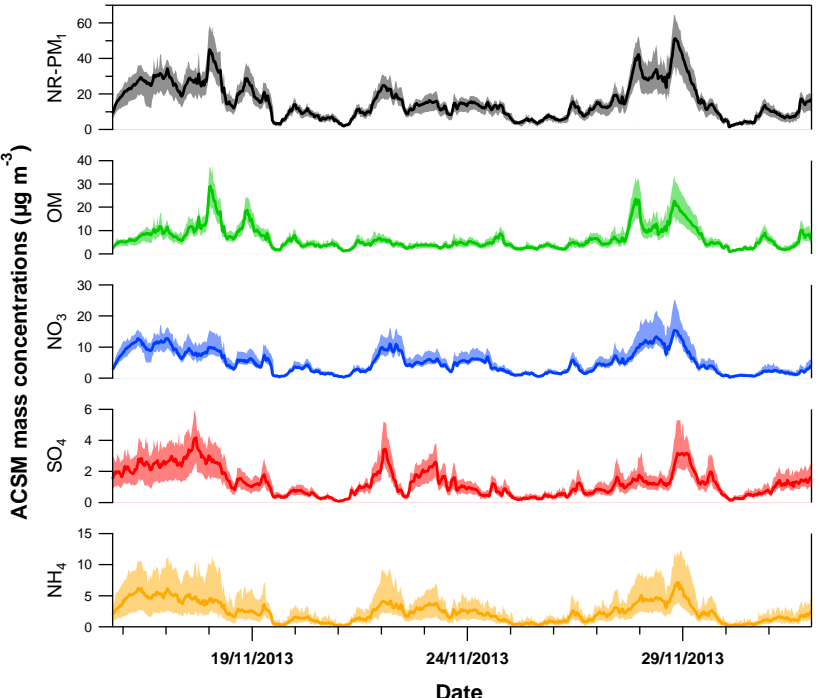

Figure 4. Averaged NR-PM 1 chemical composition and mass concentrations of Q-ACSM major component (OM, nitrate, sulfate, ammonium) measured by the 13 Q-ACSMs. Chloride mass loadings are not presented here due to the low atmospheric concentrations. Dark lines and color areas correspond to the median of Q-ACSMs and the min-max range, respectively.

3. $1<|Z| \leq 2$ are coherent and correspond to an acceptable performance;

4. $|Z| \leq 1$ are optimal and correspond to an excellent performance.

The values calculated and used for this statistical analysis are given in Table S4 in the Supplement.

Finally, Q-ACSM mass concentration uncertainties, expressed in percent, were estimated according to the ISO 13528 (2005):

$U=k \times S_{\mathrm{r}}$

where $U$ is the expanded uncertainty, $k$ is the coverage factor (chosen here as equal to 2), and $S_{\mathrm{r}}$ is the reproducibility standard deviation as defined by ISO 5725-5 (1998).

Note that, within the calculations performed in the present study, $\sigma_{\mathrm{p}}$ is directly obtained from Q-ACSM measurements (rather than from a "reference measurement"). Subsequently, $U$ only refers here to the reproducibility expanded uncertainty, which is obviously lower than the overall expanded 
uncertainty. The latter one could not be estimated here because of the lack of standard methods for online measurement of NR-PM 1 components.

\section{Results and discussion}

Both the reproducibility of Q-ACSM measurements (NR$\mathrm{PM}_{1}, \mathrm{OM}, \mathrm{NO}_{3}, \mathrm{SO}_{4}, \mathrm{Cl}, \mathrm{NH}_{4}$ ) and their consistency with results obtained from other co-located instruments are presented and discussed in this section. The reproducibility was estimated using standard deviation and $Z$ score analyses. The results reflect how comparable the data obtained from different Q-ACSMs are, even if they are far from the actual value. The consistency of Q-ACSM measurements was then addressed by comparing robust median Q-ACSM concentrations to other independent co-located aerosol measurements.

\subsection{Reproducibility of Q-ACSM measurements}

\subsubsection{Reproducibility of Q-ACSM mass concentration results}

For each Q-ACSM, the average relative contributions of different species to total NR-PM 1 are reported in Fig. 4a. The temporal variability of the median mass concentrations and ranges (minimum, maximum) of NR-PM $1, \mathrm{OM}, \mathrm{NO}_{3}, \mathrm{SO}_{4}$, $\mathrm{NH}_{4}$, and $\mathrm{Cl}$ measured by the $13 \mathrm{Q}$-ACSMs are shown in Fig. 4b. The chemical mass composition found here is very similar to the one reported in Crippa et al. (2013b) and Petit et al. (2014) during wintertime at the same sampling site (SIRTA).

NR-PM $\mathrm{P}_{1}$ is dominated by the organic fraction ranging from 34 to $43 \%$ (average of $39 \%$ ) followed by nitrate ranging from 29 to $40 \%$ (average of $34 \%$ ), sulfate ranging from 6.8 to $19 \%$ (average of $13 \%$ ) and ammonium ranging from 6.1 to $19 \%$ (average of $14 \%$ ). Finally, chloride contribution to the total NR-PM $\mathrm{PM}_{1}$ mass concentration was very low $(1.0 \pm 0.6 \%)$.

Linear correlation plots for NR-PM $1, \mathrm{OM}, \mathrm{SO}_{4}, \mathrm{NO}_{3}$, $\mathrm{NH}_{4}$, and $\mathrm{Cl}$ mass concentrations are shown in Fig. 5 for each Q-ACSM when compared to the median values ( $30 \mathrm{~min}$ time resolution, $N=780$ ). Except for chloride, correlations are very good for each instrument, with $r^{2}$ systematically higher than 0.89. Nevertheless, some slope discrepancies could be observed. In particular, Q-ACSMs no. 7 and 2 showed the highest relative deviations to the median (RDM) for the measurements of NR-PM 1 (slopes of 0.71 and 1.19 , respectively) and OM (slopes of 0.70-1.37, respectively). Ten Q-ACSMs showed RDM values lower than $20 \%$ for both NR-PM 1 and $\mathrm{OM}$. For $\mathrm{NO}_{3}$, the slopes varied from 0.84 (Q-ACSM no. 4) to 1.43 (Q-ACSM no. 2), while for $\mathrm{SO}_{4}$ they varied from 0.62 (Q-ACSM no. 10) to 1.47 (Q-ACSM no. 5). The highest RDM was observed for $\mathrm{NH}_{4}$ and $\mathrm{Cl}$ measurements. Slopes for $\mathrm{NH}_{4}$ ranged from 0.54 (Q-ACSM no. 2) to 1.88 (QACSM no. 9), while slopes for $\mathrm{Cl}$ ranged from 0.70 to 1.37 , excluding Q-ACSMs no. 2, 10, and 13 for which observed correlations were too weak. Chloride discrepancies might be due to the very low concentrations during the sampling period, close to the Q-ACSM detection limits as it was observed by Budisulistiorini et al. (2014) and Fröhlich et al. (2013). The vaporization behavior might also be less ideal for chlorides, which are more likely to depend on the specific conditions around the heater/ion source.

Interestingly, higher RDMs were observed for each individual chemical component than for the NR-PM $\mathrm{PMM}_{1}$, suggesting compensating errors and pointing out the need to perform comparisons at chemical levels. Our results agree however with the only Q-ACSM intercomparison study reported in the literature and carried out by Budisulistiorini et al. (2014), for which a deviation of $9 \%$ was observed for NR-PM 1 measurements from two instruments, while higher differences were found for $\mathrm{OM}, \mathrm{SO}_{4}, \mathrm{NH}_{4}$, and $\mathrm{Cl}(14,27$, 21 , and $40 \%$, respectively), except for $\mathrm{NO}_{3}$ for which a difference of $2 \%$ was observed.

The very good correlation coefficients $\left(r^{2}\right)$ observed here are primarily related to the use of a unique fragmentation table. They also reflect the ability of the different instruments to properly focus the particle beam onto the vaporization region. The reasons behind the discrepancies observed in RDM for each individual chemical component could be multiple and remain partly unclear here. No links could be made between Q-ACSM discrepancies and their location in the laboratory, highlighting the similar sampling conditions. Furthermore, unsatisfactory $\mathrm{RF}_{\mathrm{NO}_{3}}$ determination for some instruments would theoretically lead to comparable biases for $\mathrm{NO}_{3}$ and $\mathrm{OM} \mathrm{RDM}$, which is not clearly observable here. However, it is to note that the biases between Q-ACSM SO 4 measurements could be partly due to the use of a constant $\mathrm{RIE}_{\mathrm{SO}_{4}}$ of 1.2.

As shown in Fig. 6, the $Z$ score values for NR-PM 1 mass concentration assigned to the Q-ACSM no. 7 and 10 indicate an unsatisfactory performance $(|Z|>3)$ with $|Z|$ of 3.4 and 3.1, respectively. The Q-ACSM no. 4 falls in the "warning area" $(2<|Z| \leq 3)$ with a $|Z|$ value of 2.8 . These three QACSMs show systematically negative $Z$ score values for all the individual chemical components, leading to a large nega-

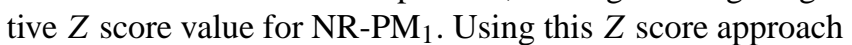
could then allow illustrating possible $\mathrm{IE}_{\mathrm{NO}_{3}}$ miscalibrations for these 3 Q-ACSMs. Another explanation may be that these three instruments sampled a smaller size fraction than the other Q-ACSMs due to a slight difference in the transmission of the aerodynamic lens leading to an underestimation of aerosol chemical mass concentrations. The remaining 10 Q-ACSMs are coherent and correspond to an acceptable or

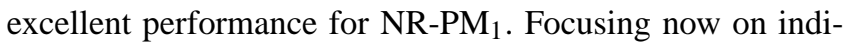
vidual chemical components, two Q-ACSMs (no. 2 and 9) were identified within the warning area for $\mathrm{NO}_{3}$ and $\mathrm{NH}_{4}$ with values of 2.4 and 2.6. For ammonium, interferences with air and water fragments $\left(\mathrm{HO}^{+}\right.$and $\mathrm{O}^{+}$at $m / z 17$ and 16) could partly explain these results (Ng et al., 2011b). The 
(a)

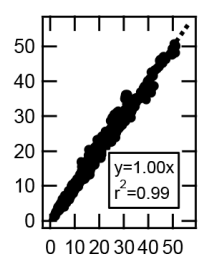

Median of ACSMs

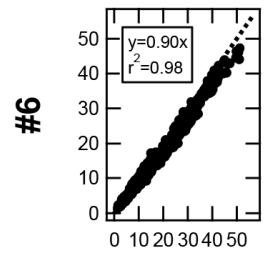

Median of ACSMs

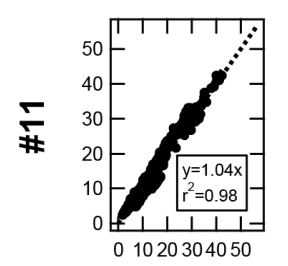

Median of ACSMs

(b)

\#

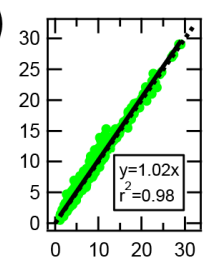

Median of ACSMs
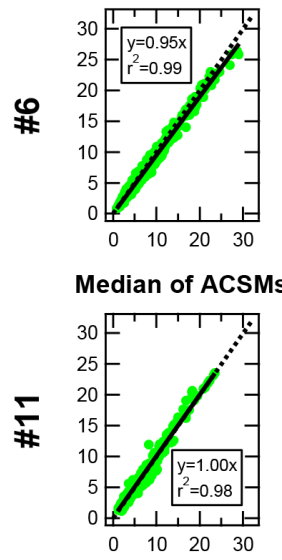

Median of ACSMs
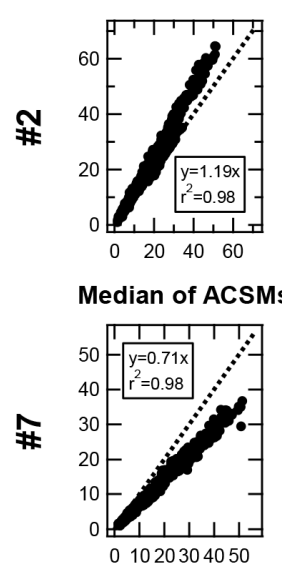

Median of ACSMs

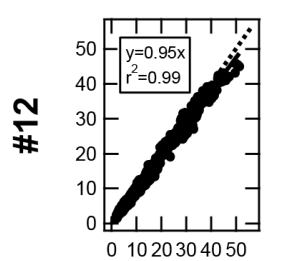

Median of ACSMs
\#

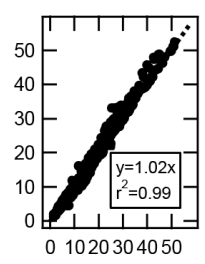

Median of ACSMs

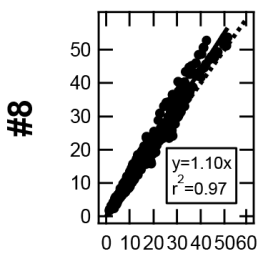

Median of ACSMs

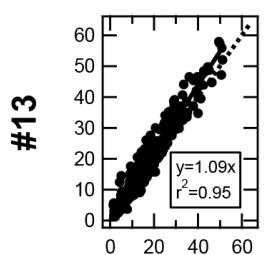

Median of ACSMs
\#

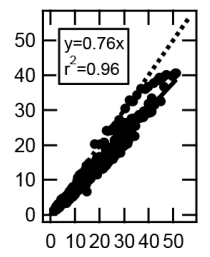

Median of ACSMs

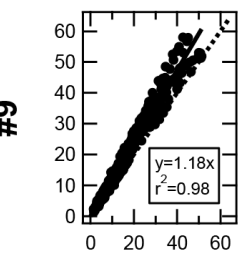

Median of ACSMs

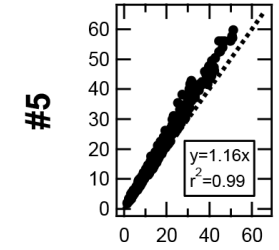

Median of ACSMs

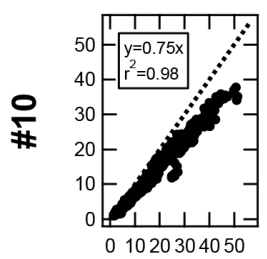

Median of ACSMs
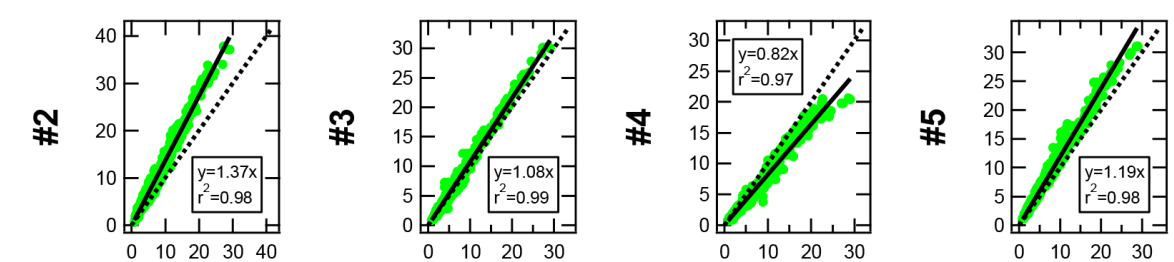

Median of ACSMs

Median of ACSMs

\#
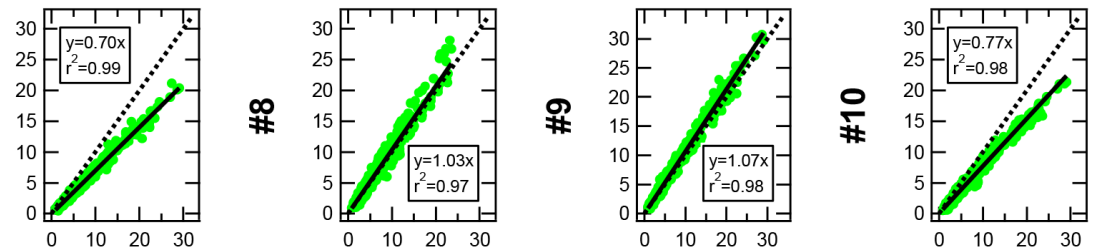

Median of ACSMs

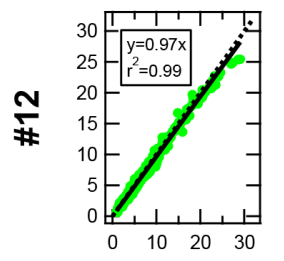

Median of ACSMs

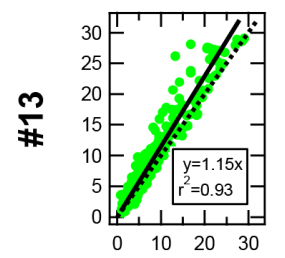

Median of ACSMs

Figure 5. 
(c)

\#

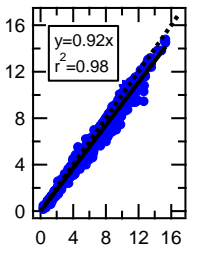

Median of ACSMs

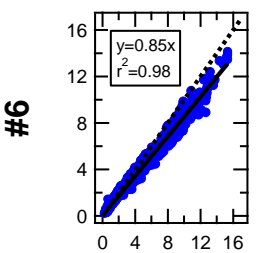

Median of ACSMs

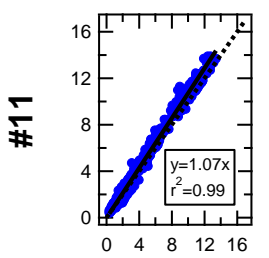

Median of ACSMs

(d)

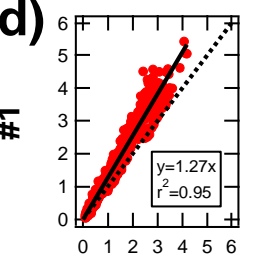

Median of ACSMs

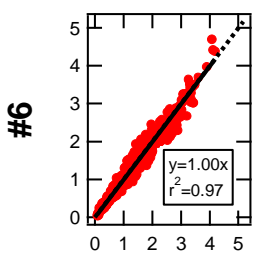

Median of ACSMs

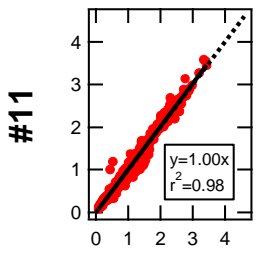

Median of ACSMs

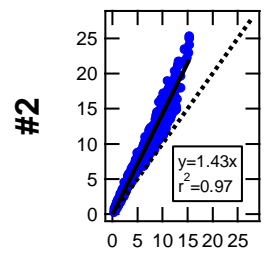

Median of ACSMs

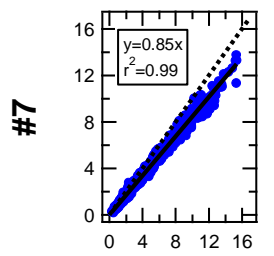

Median of ACSMs

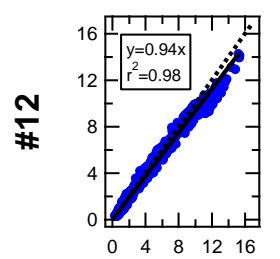

Median of ACSMs
$¥$

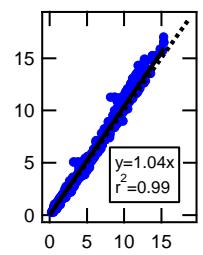

Median of ACSMs

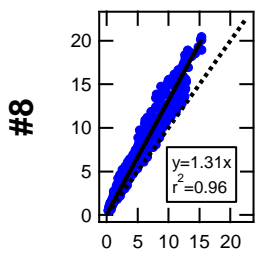

Median of ACSMs

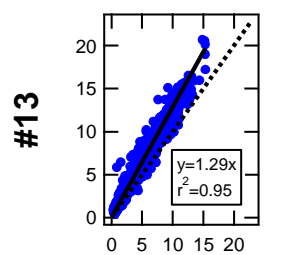

Median of ACSMs

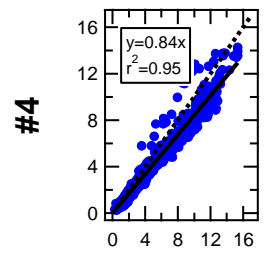

Median of ACSMs

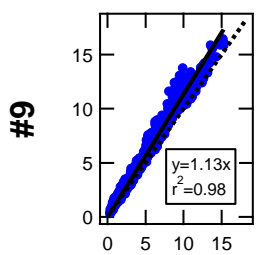

Median of ACSMs

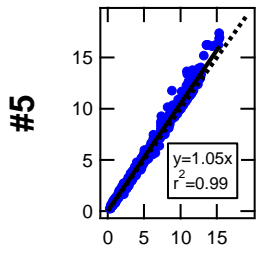

Median of ACSMs

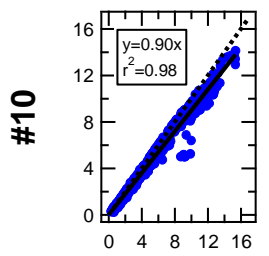

Median of ACSMs
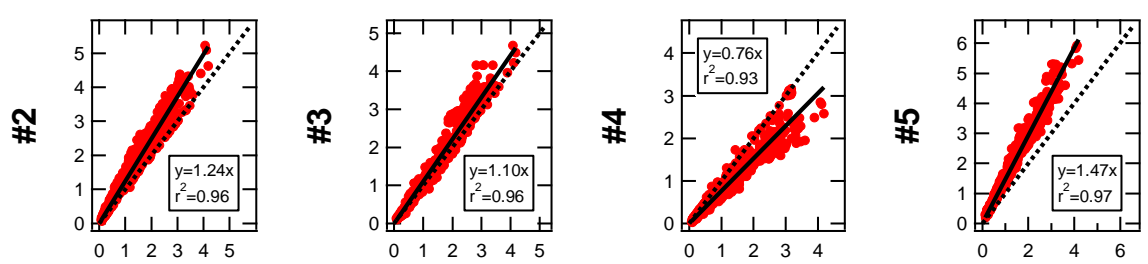

Median of ACSMs

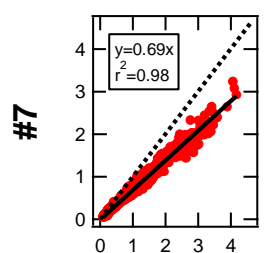

Median of ACSMs
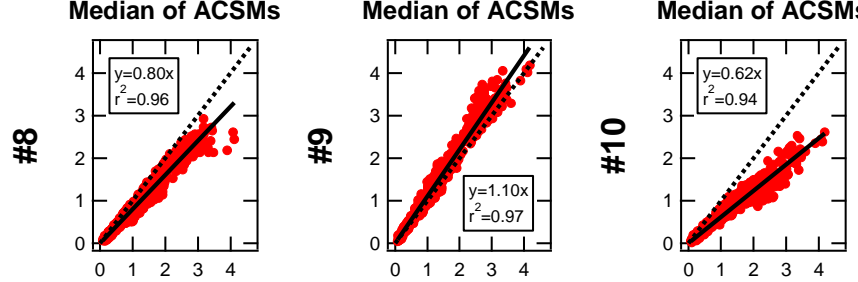

Median of ACSMs

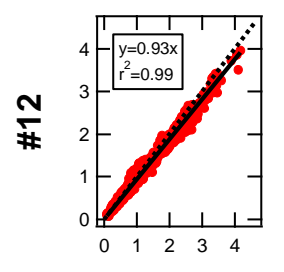

Median of ACSMs

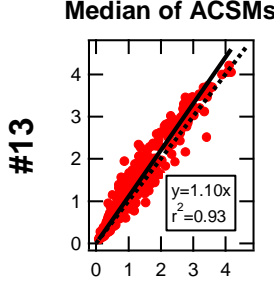

Median of ACSMs

Figure 5. 

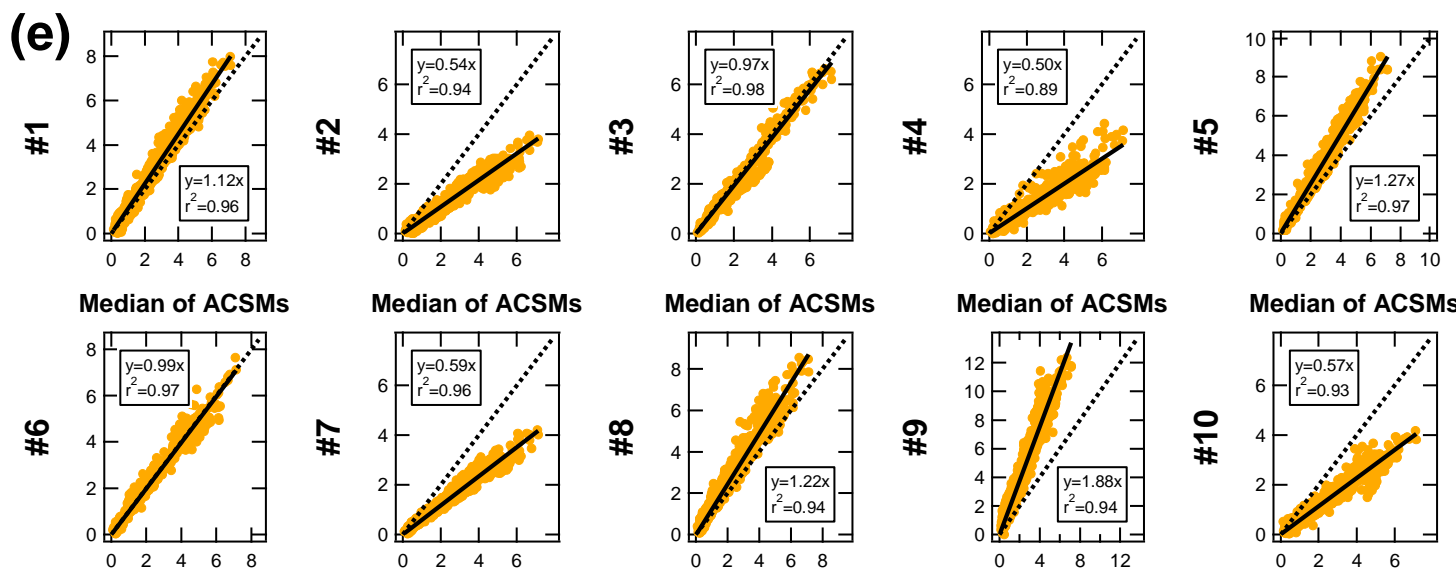

Median of ACSMs
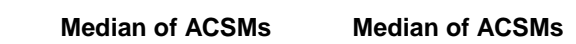

Median of ACSMs
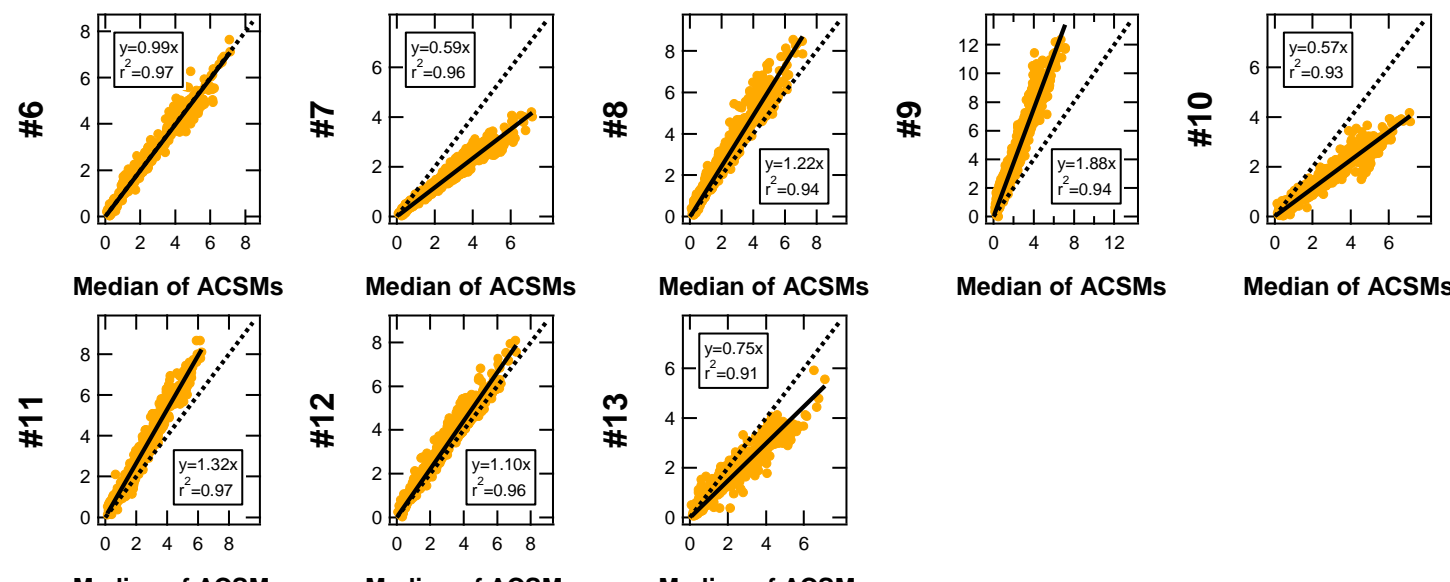

Median of ACSMs

Median of ACSMs

Median of ACSMs

Median of ACSMs

Median of ACSMs
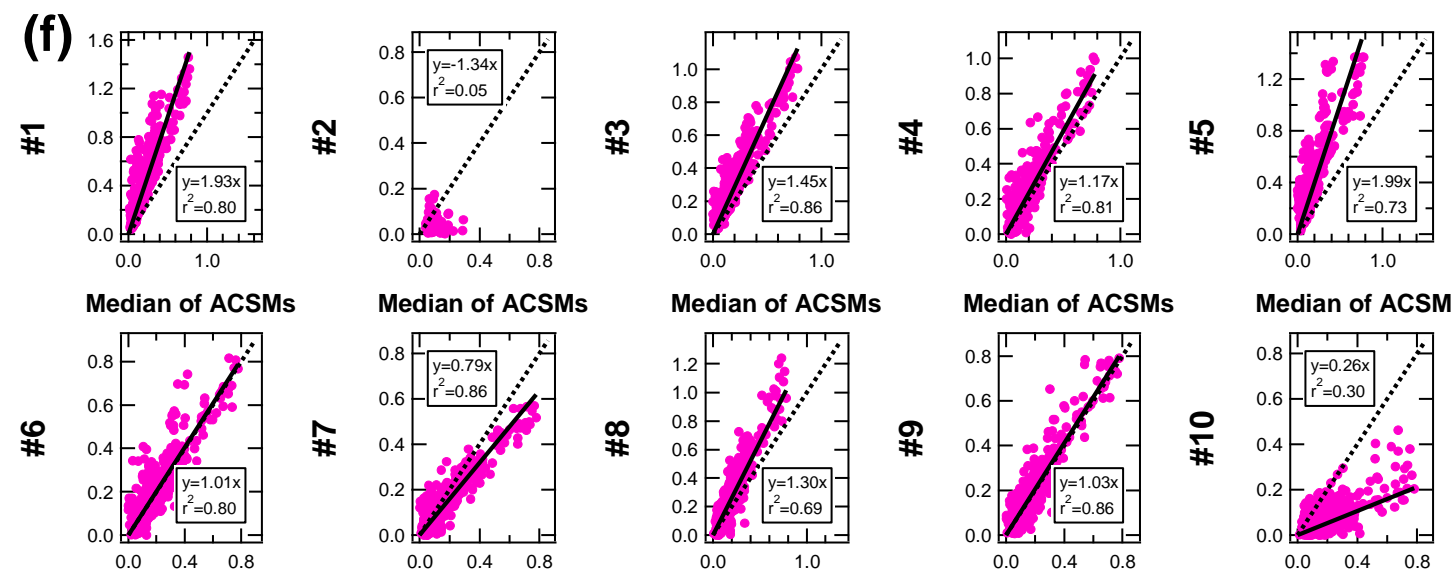

Median of ACSMs
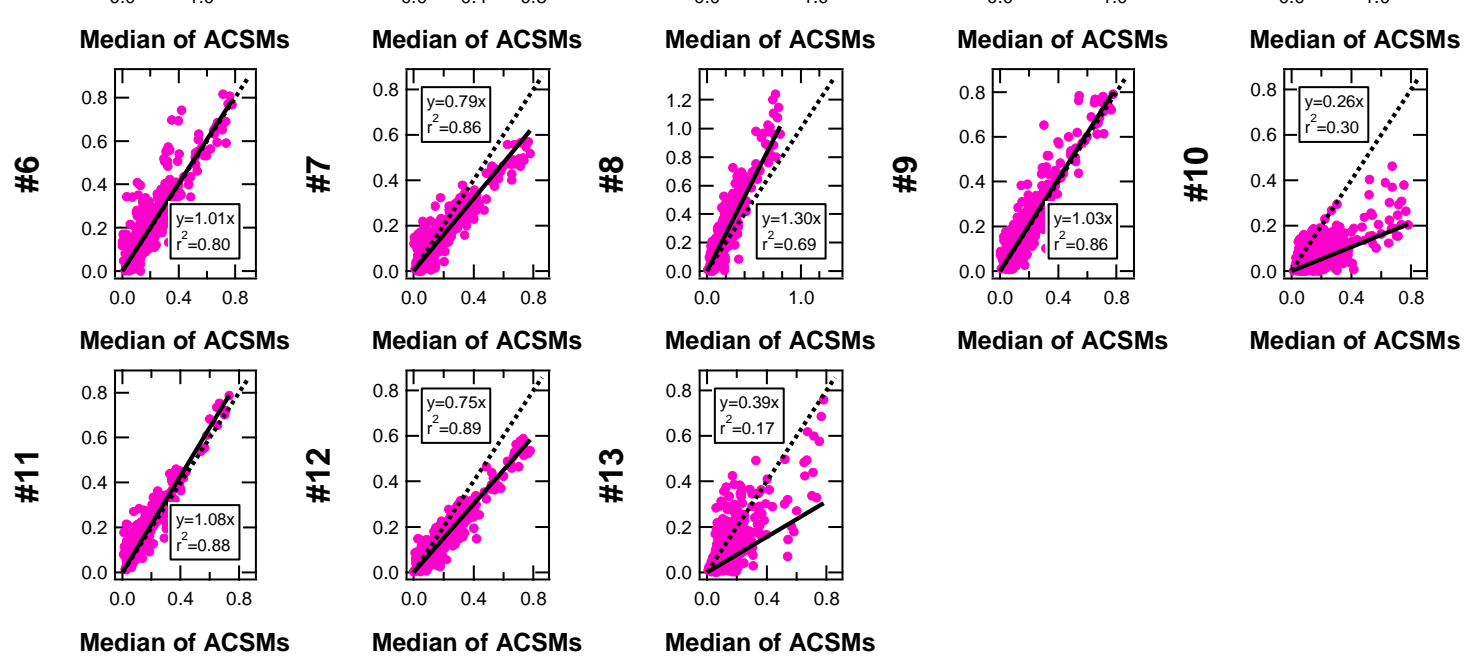

Figure 5. Scatter plots of (a) NR-PM 1 , (b) OM, (c) nitrate, (d) sulfate, (e) ammonium, and (f) chloride mass concentrations in $\mu \mathrm{g} \mathrm{m}^{-3}$ measured by each Q-ACSM vs. the median of all the 13 Q-ACSMs. Dotted line is the $1: 1$ line. Full lines represent the orthogonal distance regression fits with zero intercept. 


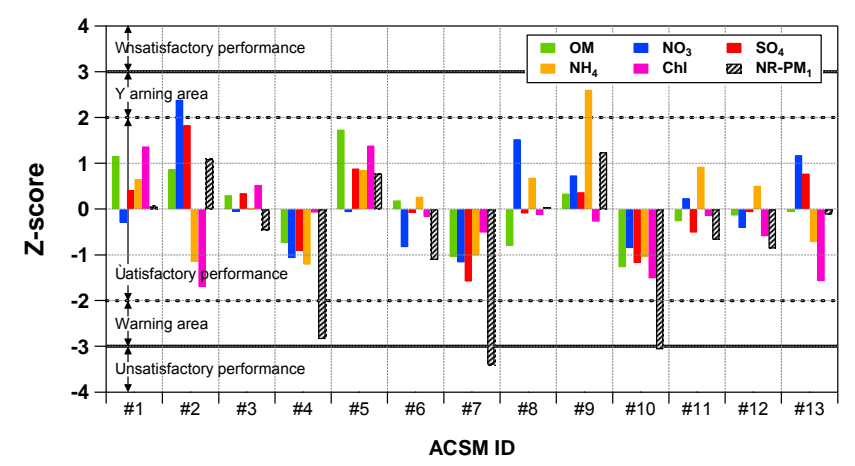

Figure 6. Statistical $Z$ score results for NR-PM 1 and their major components measured by the 13 Q-ACSMs.

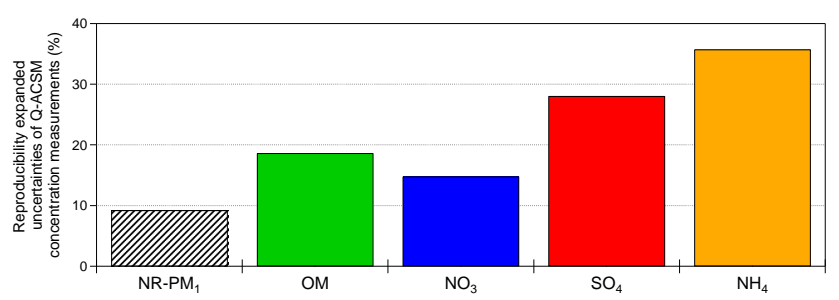

Figure 7. Reproducibility expanded uncertainties of the Q-ACSM non-refractory submicron particulate matter $\left(\mathrm{NR}-\mathrm{PM}_{1}\right)$ mass concentrations and its major component (organic matter, OM; nitrate, $\mathrm{NO}_{3}$; sulfate, $\mathrm{SO}_{4}$; and ammonium, $\mathrm{NH}_{4}$ ). Chloride-measurement expanded uncertainty is not presented here due to the low atmospheric concentrations.

$Z$ score analysis for all the other components $\left(\mathrm{OM}, \mathrm{SO}_{4}\right.$ and $\mathrm{Cl}$ ) showed satisfactory results with $|Z|$ values below 2 highlighting a rather low dispersion of the measured data.

Figure 7 presents the results obtained from reproducibility expanded uncertainty calculations. The lowest reproducibility expanded uncertainty was found for NR-PM $19 \%$ ), followed by $\mathrm{NO}_{3}(15 \%)$ and $\mathrm{OM}(19 \%)$. $\mathrm{SO}_{4}$ and $\mathrm{NH}_{4}$ present reproducibility expanded uncertainties higher by a factor of 2 compared to $\mathrm{NO}_{3}$ and $\mathrm{OM}$ with values of 28 and $36 \%$, respectively. These results might be due to the uncertainty linked to the determination of $\mathrm{RIE}_{\mathrm{SO}_{4}}$ (taken here as constant). Our results are in agreement with a recent study performed by Budisulistiorini et al. (2014), where an Q-ACSM accuracy around $30 \%$ was estimated using a compositiondependent CE parameterization (Middlebrook et al., 2012).

\subsubsection{Reproducibility of Q-ACSM fragmentation patterns}

As performed for Q-ACSM mass concentration data, statistical analyses were performed for the most important inorganic and organic fragments $(m / z)$. Results of the latter tests are presented in Sect. S5 in the Supplement. Regarding the $Z$ score analysis results, only 1 Q-ACSM (no. 1) showed unsatisfactory performances, with a significant positive system-
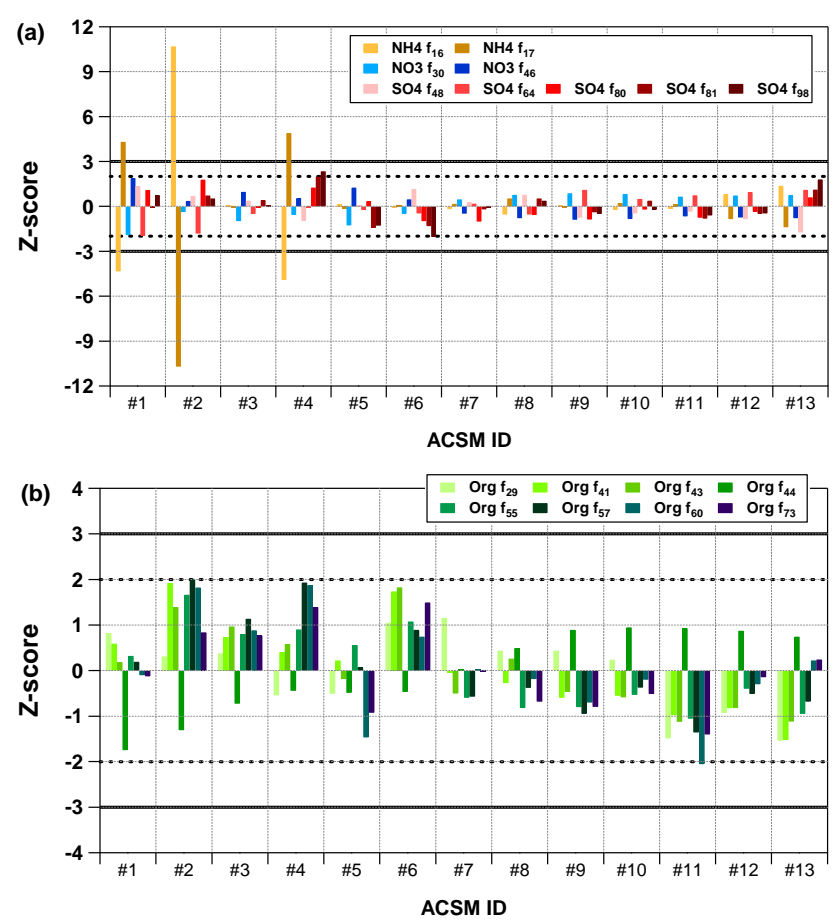

Figure 8. Statistical $Z$ score results for major Q-ACSM fragments $\left(f_{m / z}\right)$ associated to (a) inorganics $\left(f_{16}\right.$ and $f_{17}$ for ammonium, $f_{30}$ and $f_{46}$ for nitrate, and $f_{48}, f_{64}, f_{80}, f_{81}$, and $f_{98}$ for sulfate) and (b) organic matter $\left(f_{29}, f_{41}, f_{43}, f_{44}, f_{55}, f_{57}, f_{60}\right.$, and $\left.f_{73}\right)$.

atic error with outliers for $\mathrm{NO}_{3}$ signal at $m / z 46$, for all the $\mathrm{SO}_{4}$ signals as well as for some of the major organic fragments. An explanation for this behavior could be due to a small leak in the quadrupole region identified after the intercomparison exercise, which also explains the unstable and higher AB signal of this Q-ACSM no. 1, with an averaged value $35 \%$ higher than the target value of $10^{-7} \times \mathrm{A}$ for this Q-ACSM. All the other Q-ACSMs showed satisfactory results, with absolute $Z$ score values $(|Z|)$ below 2 for most of them (except Q-ACSM no. 9 and 12, showing values between 2 and 3 for some $m / z$ ), denoting a coherent and good performance for most of the Q-ACSMs.

Statistical analyses were then applied to the relative contribution of major individual $\mathrm{m} / \mathrm{z}$ to the total mass ( $f$ values) for the most important inorganic and organic fragments (Fig. 8). Three Q-ACSMs (no. 1, 2, and 4) were clearly identified above the warning area for $\mathrm{NH}_{4}$ with $|Z|$ values of $4.3,10.7$ and 4.9 , respectively showing opposite patterns of $Z$ score values for $f_{16}$ and $f_{17}$. High $|Z|$ values might be due to large interferences of $\mathrm{NH}_{4}$ fragments with water, which increases the measurement uncertainties. The $Z$ score analysis for all the other $f_{m / z}\left(\mathrm{OM}, \mathrm{SO}_{4}\right.$, and $\left.\mathrm{NO}_{3}\right)$ showed satisfactory results with $|Z|$ values below or close to 2 in agreement with the $Z$ score analysis on the individual chemical components. 
Table 4. Overview of the scatter plot results of the major organic and inorganic $f_{m / z}$ (defined as the ratio of organic $m / z$ to the total organic mass signals) measured by each Q-ACSM vs. the median of all the Q-ACSMs during the intercomparison study. Results summarized here present the slopes from the orthogonal distance regression fit with zero intercept. Slopes $\leq 10 \%$ of the $1: 1$ line in bold; > $20 \%$ in italic.

\begin{tabular}{|c|c|c|c|c|c|c|c|c|c|c|c|c|c|c|c|c|c|}
\hline \multirow[b]{2}{*}{ ACSM \# } & \multicolumn{8}{|c|}{ Organic fragments } & \multicolumn{9}{|c|}{ Inorganic fragments } \\
\hline & $f_{29}$ & $f_{41}$ & $f_{43}$ & $f_{44}$ & $f_{55}$ & $f_{57}$ & $f_{60}$ & $f_{73}$ & $f_{16}$ & $f_{17}$ & $f_{30}$ & $f_{46}$ & $f_{48}$ & $f_{64}$ & $f_{80}$ & $f_{81}$ & $f_{98}$ \\
\hline 1 & 1.07 & 1.06 & 1.02 & 0.59 & 1.04 & 1.02 & 0.97 & 0.97 & 0.81 & 1.19 & 0.84 & 1.62 & 1.12 & 0.84 & 1.25 & 1.04 & 1.16 \\
\hline 2 & 1.02 & 1.18 & 1.18 & 0.69 & 1.21 & 1.27 & 1.17 & 1.14 & 1.43 & 0.60 & 0.95 & 1.19 & 1.06 & 0.85 & 1.39 & 1.17 & 1.12 \\
\hline 3 & 1.02 & 1.07 & 1.12 & 0.83 & 1.11 & 1.15 & 1.08 & 1.12 & 0.98 & 1.01 & 0.90 & 1.37 & 1.04 & 0.96 & 1.00 & 1.12 & 0.99 \\
\hline 4 & 0.93 & 1.04 & 1.07 & 0.87 & 1.12 & 1.26 & 1.17 & 1.23 & 0.86 & 1.26 & 0.94 & 1.24 & 0.92 & 1.00 & 1.28 & 1.49 & 1.44 \\
\hline 5 & 0.94 & 1.03 & 0.99 & 0.86 & 1.09 & 1.04 & 0.86 & 0.86 & 1.00 & 1.01 & 0.88 & 1.47 & 1.01 & 0.98 & 1.11 & 0.66 & 0.75 \\
\hline 6 & 1.07 & 1.17 & 1.22 & 0.90 & 1.14 & 1.12 & 1.08 & 1.22 & 0.98 & 1.02 & 0.94 & 1.22 & 1.10 & 0.96 & 0.83 & 0.69 & 0.58 \\
\hline 7 & 1.10 & 1.00 & 0.95 & 0.99 & 0.94 & 0.93 & 0.99 & 0.99 & 0.98 & 1.02 & 1.01 & 0.94 & 1.03 & 1.02 & 0.82 & 0.96 & 0.98 \\
\hline 8 & 1.03 & 0.98 & 1.04 & 1.10 & 0.91 & 0.96 & 0.98 & 0.88 & 0.96 & 1.03 & 1.04 & 0.85 & 1.07 & 0.96 & 0.90 & 1.12 & 1.05 \\
\hline 9 & 1.04 & 0.95 & 0.95 & 1.19 & 0.92 & 0.89 & 0.93 & 0.88 & 0.99 & 1.01 & 1.05 & 0.82 & 0.94 & 1.09 & 0.86 & 0.93 & 0.89 \\
\hline 10 & 1.01 & 0.96 & 0.94 & 1.20 & 0.95 & 0.96 & 0.99 & 0.93 & 0.98 & 1.03 & 1.04 & 0.84 & 0.96 & 1.05 & 0.99 & 1.11 & 0.96 \\
\hline 11 & 0.85 & 0.91 & 0.87 & 1.15 & 0.89 & 0.84 & 0.83 & 0.80 & 0.98 & 1.02 & 1.03 & 0.90 & 0.97 & 1.06 & 0.90 & 0.83 & 0.90 \\
\hline 12 & 0.90 & 0.93 & 0.90 & 1.18 & 0.96 & 0.94 & 0.97 & 0.98 & 1.02 & 0.99 & 1.03 & 0.86 & 0.93 & 1.08 & 0.96 & 0.88 & 0.88 \\
\hline 13 & 0.86 & 0.85 & 0.88 & 1.16 & 0.88 & 0.90 & 0.97 & 1.01 & 1.04 & 0.97 & 1.03 & 0.87 & 0.85 & 1.09 & 1.14 & 1.27 & 1.34 \\
\hline
\end{tabular}
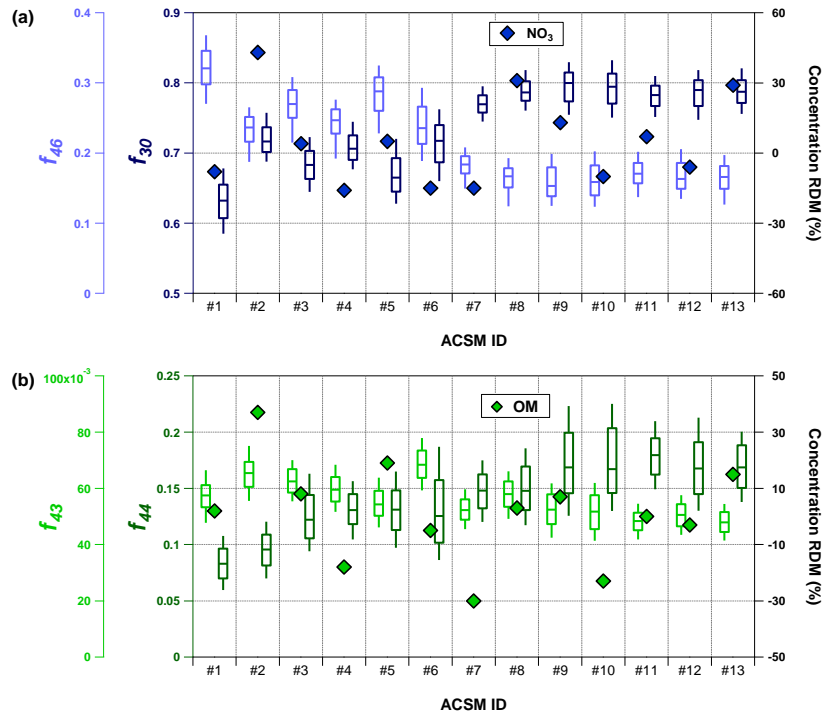

Figure 9.

Deviation of $f_{m / z}$ values from RDM are presented in Table 4 and discussed in the following. Q-ACSM $\mathrm{NO}_{3}$ mass concentrations are derived from the measured $\mathrm{m} / \mathrm{z} 30$ and $m / z 46$ ion signals. As shown in Fig. 9a, there is a clear opposite tendency of $f_{30}$ and $f_{46}$ values leading to positive RDM for $f_{46}$ when negative $f_{30}$ is observed, and vice versa (Table 4). This pattern reflects that when one goes up, the other go down to keep the total $\mathrm{NO}_{3}$ signal the same. This feature is strikingly consistent with the distribution of $f_{44}$ (Fig. 9b). Negative RDM in $f_{44}$ (positive RDM in $f_{44}$ ) being concomitant with negative RDM for $f_{30}$ (positive RDM for $f_{46}$ ). In other words, Q-ACSM fragmentation issues for OA also affects the fragmentation pattern of inorganic species with the same extent (e.g., the higher $f_{44}$ RDM being con-
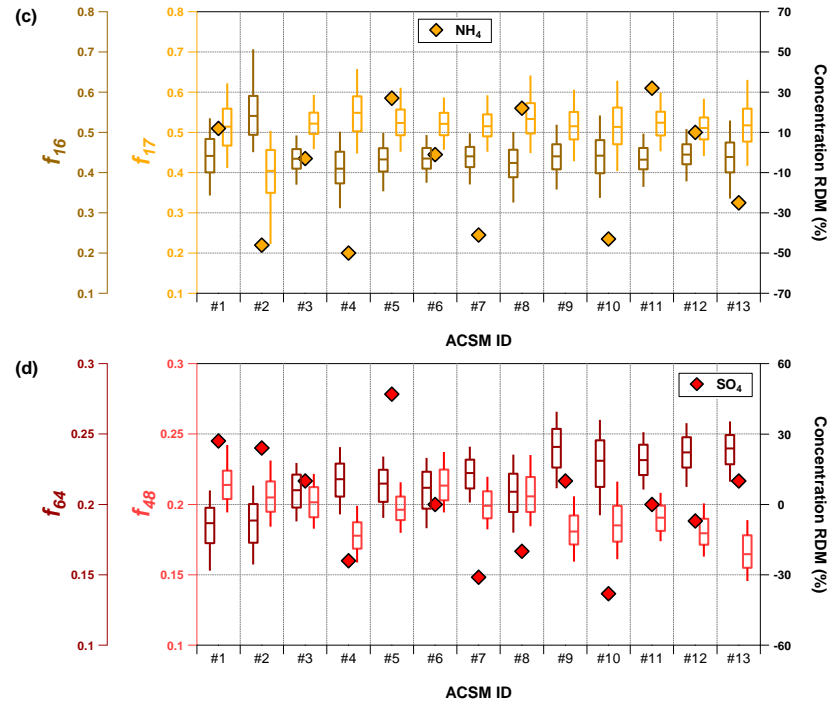

Figure 9. Relative deviation to the median (RDM) of Q-ACSM concentrations and box plots of $f_{m} / z$ values for (a) $\mathrm{NO}_{3}\left(f_{30}\right.$ and $\left.f_{46}\right)$, (b) $\mathrm{OM}\left(f_{43}\right.$ and $\left.f_{44}\right)$, (c) $\mathrm{NH}_{4}\left(f_{16}\right.$ and $\left.f_{17}\right)$, (d) $\mathrm{SO}_{4}\left(f_{48}\right.$ and $\left.f_{64}\right)$. The median, the 25 th and 75 th percentiles are represented by the middle, lower and upper vertical bars, respectively. The 10th and the 90th percentiles are the bottom and top limits of the horizontal bars, respectively.

comitant with the higher $f_{30} \mathrm{RDM}$ ). Based on a similar contribution to the total $\mathrm{NH}_{4}$ signal, the $f_{16}$ and $f_{17} \mathrm{RDMs}$ cancel each other out (Fig. 9c), like for the Q-ACSM no. 2 which presents the highest values (43 and $40 \%$, respectively). No trends in the fragmentation pattern are observed for $f_{16}$ and $f_{17}$ (as observed for $f_{44}$ or $f_{30}$, for instance). For sulfate, $f_{48}$ and $f_{64}$ contributed both around $45 \%$ to the total $\mathrm{SO}_{4}$ signal (Fig. 9d). Most of the time they compensate each other 

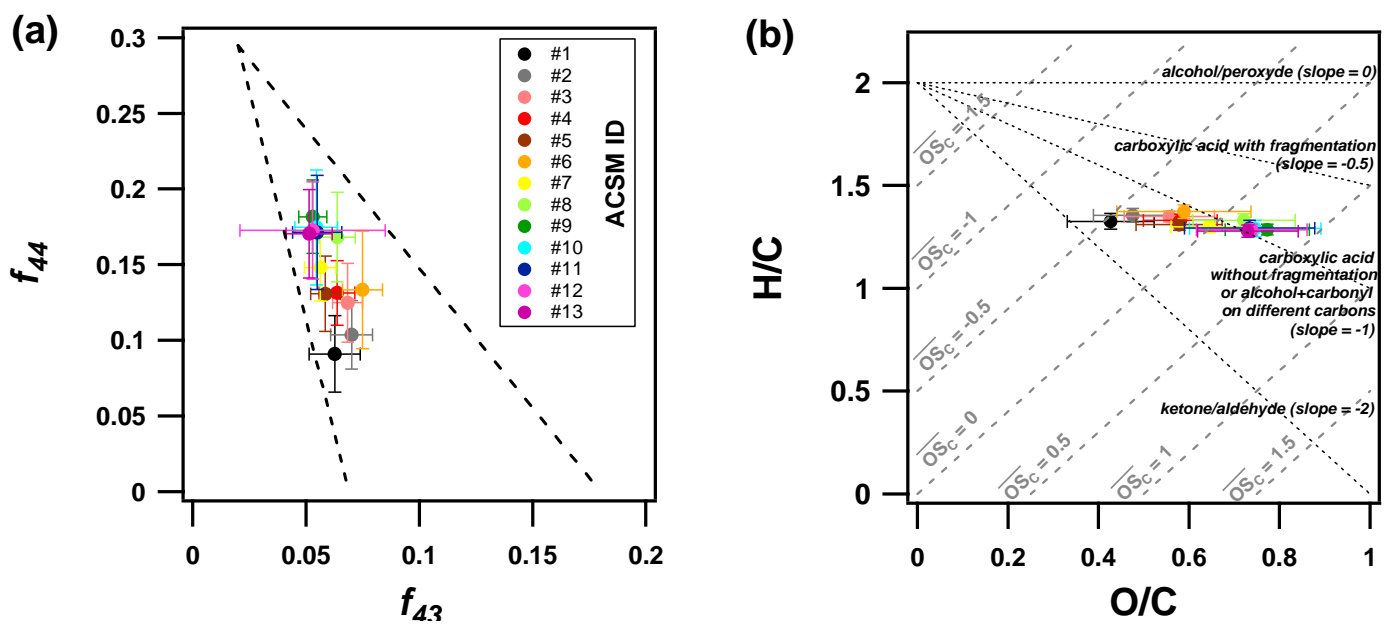

Figure 10. Averaged values of (a) $f_{44}$ vs $f_{43}$ and (b) $\mathrm{H} / \mathrm{C}$ vs O / C determined for the $13 \mathrm{Q}$-ACSMs. The error bars correspond to 1 standard deviation $( \pm 1 \sigma)$. The oxidation state $\left(\overline{\mathrm{OS}}_{\mathrm{C}}\right)$ was calculated as $\overline{\mathrm{OS}}_{\mathrm{C}} \approx 2 \mathrm{O} / \mathrm{C}-\mathrm{H} / \mathrm{C}$ according to Kroll et al. (2011).

(RDM opposite in sign) and show a slight trend with positive $f_{48}$ (negative $f_{64}$ ) for negative $f_{44}$ RDM (i.e., the first Q-ACSMs) and negative $f_{48}$ (positive $f_{64}$ ) for positive $f_{44}$ RDM (i.e., the last Q-ACSMs). Interestingly, RDM high deviations are amplified since ion signals are often small like for the $\mathrm{SO}_{4}$ fragments where $f_{48}$ and $f_{64}$, which contribute strongly to the total $\mathrm{SO}_{4}$ signal show lower RDMs than $f_{80}$, $f_{81}$, and $f_{98}$ (Table 4). Part of the discrepancies might be due to interferences between $\mathrm{SO}_{4}$ and $\mathrm{OA}$ fragments for a same nominal mass. For example, Budisulistiorini et al. (2014) reported that the $m / z 30$ ion measured by the Q-ACSM is likely to be influenced by small contributions of fragments other than nitrates, such as oxygenated organics $\left(\mathrm{CH}_{2} \mathrm{O}^{+}\right)$ and/or organic-nitrate compounds $\left(\mathrm{CH}_{4} \mathrm{~N}^{+}\right)$. Oxygenated organics $\left(\mathrm{CH}_{4} \mathrm{O}_{2}^{+}\right)$and hydrogenated organics $\left(\mathrm{C}_{5} \mathrm{H}_{4}^{+}\right)$could also induce bias by contributing to $\mathrm{SO}_{4}$ signal at $\mathrm{m} / z$ 48 and 64 , respectively.

Such a detailed investigation of the relative ion intensities of Q-ACSM fragments are of prime interest since $f_{m / z}$ values can provide crucial information about the presence of specific organic aerosol (OA) factors such as hydrocarbonlike OA (i.e., $\left.f_{55}, f_{57}\right)$, oxygenated-like OA $\left(f_{29}, f_{41}, f_{43}\right.$, $\left.f_{44}\right)$ or biomass-burning OA $\left(f_{60}\right.$, and $\left.f_{73}\right)$, and are used for OA source apportionment analysis (Ng et al., 2010, 2011b). Moreover, these fragments are used for empirically estimating elemental ratios $(\mathrm{O} / \mathrm{C}, \mathrm{H} / \mathrm{C}$; $\mathrm{Ng}$ et al., 2011b) and the OA oxidation state $\left(\overline{\mathrm{OS}}_{\mathrm{C}}\right.$; Kroll et al., 2011), both of which are derived from AMS calibrations. The relative deviation to the median (RDM) for the following fragments, $f_{29}, f_{41}, f_{43}$, $f_{44}, f_{55}, f_{57}, f_{60}$, and $f_{73}$ are reported in Table 4 . The high variability in $f_{44}$ can have important implications for the calculation of $\mathrm{O} / \mathrm{C}$ and $\overline{\mathrm{OS}}_{\mathrm{C}}$, as illustrated in Fig. 10. For example, the $\mathrm{O} / \mathrm{C}$ and $\overline{\mathrm{OS}}_{\mathrm{C}}$ values obtained from $f_{44}$ using previously published parameterizations (Aiken et al., 2008) are highly variable for this data set, which shows $\mathrm{O} / \mathrm{C}$ ra- tios ranging from 0.43 to 0.77 and $\overline{\mathrm{OS}}_{\mathrm{C}}$ ranging from -0.47 to 0.26 . The $\mathrm{O} / \mathrm{C}$ parameterization from Aiken et al. (2008) and the triangle plot from $\mathrm{Ng}$ et al. (2011b) should then be used and interpreted with caution for Q-ACSMs. This variability appears to be independent of the organic mass concentrations and could be due to instrument-dependent differences in the vaporization conditions. Work is in progress to understand this variability. While the $f_{44}$ from these measurements is highly variable, it is interesting to note that the relative ratio of other organic ions is less variable (see Table 4). The implications for source apportionment are investigated and discussed in a companion paper (Fröhlich et al., 2015).

\subsection{Consistency of Q-ACSM measurements with co-located instruments}

The consistency of Q-ACSM results was checked using a large number of co-located instruments introduced in Sect. 3.2. As mentioned in Sect. 3.1.3, all the data were averaged with a $30 \mathrm{~min}$ time resolution $(N=780)$ for $\mathrm{PM}_{1}$ intercomparison, with a $3 \mathrm{~h}$ time resolution for on-line chemical constituent intercomparison and with a $6 \mathrm{~h}$ time resolution for off-line (filter sampling) chemical constituent intercomparison. These different temporal resolutions were selected in order to harmonize the different time resolutions of the instruments while maintaining enough mass concentration variability for correlation plots.

\subsubsection{Total mass concentrations $\left(\mathbf{P M}_{1}\right)$}

The accuracy of Q-ACSM concentrations was first evaluated from the reconstruction of $\mathrm{PM}_{1}$ mass throughout the correlation plots with independent $\mathrm{PM}_{1}$ measurements obtained directly (TEOM-FDMS) or indirectly (using specific hypotheses) from number size distribution (SMPS) or from the re- 
Table 5. Correlations with non-zero intercept fits (and zero intercept fits into brackets) of $\mathrm{PM}_{1}$ mass concentrations between Q-ACSM median and co-located instruments (TEOM-FDMS, Nephelometer, SMPS, HR-ToF-AMS, and ToF-ACSM). Data are $30 \mathrm{~min}$ averaged $(N=780)$.

\begin{tabular}{lc|r|r|r}
\hline & & \multicolumn{3}{|c}{ Q-ACSM } \\
\cline { 2 - 5 } Instruments & Mean $\pm 1 \sigma$ & Slope & Intercept & \multicolumn{1}{c}{$r^{2}$} \\
\cline { 2 - 5 } & $16.4 \pm 10.0$ & $0.941(1.01)$ & 1.57 & $0.78(0.78)$ \\
TEOM-FDMS & $12.5 \pm 9.08$ & $1.05(1.25)$ & 3.87 & $0.80(0.76)$ \\
Nephelometer $^{\mathrm{b}}$ & $10.3 \pm 5.50$ & $1.32(1.31)$ & -0.13 & $0.84(0.84)$ \\
SMPS $^{\mathrm{c}}$ & $14.2 \pm 9.49$ & $0.988(1.13)$ & 2.97 & $0.78(0.76)$ \\
HR-ToF-AMS $^{\mathrm{a}}$ & $17.3 \pm 11.0$ & $0.910(0.964)$ & 1.31 & $0.88(0.88)$ \\
ToF-ACSM $^{\mathrm{a}}$ & &
\end{tabular}

${ }^{a} \mathrm{PM}_{1}$ mass was determined from the sum of all non-refractory components $\left(\mathrm{OM}, \mathrm{NO}_{3}, \mathrm{SO}_{4}, \mathrm{NH}_{4}\right.$, and $\left.\mathrm{Cl}\right)$ and EBC mass concentrations. ${ }^{b}$ A mass scattering efficiency of $2.5 \mathrm{~m}^{2} \mathrm{~g}^{-1}$ was used to reconstruct $\mathrm{PM}_{1}$ mass (Titos et al., 2012). ${ }^{\mathrm{c}} \mathrm{PM}_{1}$ mass was calculated using an averaged aerosol density of 1.6 based on the NR-PM 1 mass composition measured by HR-ToF-AMS.

construction of the light scattering coefficient $\left(\sigma_{\mathrm{sp}}\right)$ measured in $\mathrm{PM}_{1}$ (nephelometer). On one hand, $\mathrm{PM}_{\text {chem }}$ concentrations were calculated as the sum of NR-PM 1 and EBC mass concentrations $\left(\mathrm{PM}_{\mathrm{chem}}=\right.$ sulfate + nitrate + ammonium + chloride $+\mathrm{OM}+\mathrm{EBC}$ ), using Aethalometer data for $\mathrm{EBC}$ and HR-ToF-AMS, ToF-ACSM or the median of the $13 \mathrm{Q}-$ ACSMs measurements for the other compounds. $\mathrm{PM}_{\mathrm{chem}}$ quasi-exhaustively accounts for $\mathrm{PM}_{2.5}$ in the region of Paris (Bressi et al., 2013; Crippa et al., 2013b; Freutel et al., 2013b; Petit et al., 2015). On the other hand, in addition to direct measurements of $\mathrm{PM}_{1}$ by TEOM-FDMS, the submicron mass was derived from SMPS data. Aerosol volume distribution from SMPS was integrated and converted into mass concentration using a constant density of 1.60 obtained from the mean chemical composition of NR-PM 1 and assuming spherical particles with immiscible components of different material densities $\left(1.27,1.40,1.72,1.75\right.$, and $1.78 \mathrm{~g} \mathrm{~cm}^{-3}$ for $\mathrm{OM}$, $\mathrm{Cl}, \mathrm{NO}_{3}, \mathrm{NH}_{4}$, and $\mathrm{SO}_{4}$, respectively; Duplissy et al., 2011). This average value of 1.60 agrees well with the averaged value of 1.58 calculated by comparing SMPS and HR-ToFAMS volume/mass distributions. Furthermore, as presented in the Supplement (Sect. S6), the use of a time-dependent density (instead of a constant one) does not significantly improve the comparison between SMPS and median Q-ACSM values. Finally, $\mathrm{PM}_{1}$ mass was also estimated from light scattering coefficient measurements using a mass scattering coefficient of $2.5 \mathrm{~m}^{2} \mathrm{~g}^{-1}$, which is an average of values commonly reported in the literature for mass scattering of fine aerosols (Chow et al., 2002; Hand and Malm, 2007; Titos et al., 2012).

Results of the $\mathrm{PM}_{1}$ intercomparison are provided in Table 5 in terms of slopes and intercepts (forced and not forced through zero) between the median of Q-ACSM and TEOM-FDMS, Nephelometer, SMPS, HR-ToF-AMS and ToF-ACSM. All the scatter plots of $\mathrm{PM}_{1}$ measurements are available in the Supplement (see Sect. S6). The median Q-ACSM and TEOM-FDMS PM 1 averaged concentrations are very similar (16.9 and $16.4 \mu \mathrm{g} \mathrm{m}^{-3}$, respectively). They correlate well $\left(r^{2}=0.78\right)$ with a slope of 0.94 and an intercept of $1.57 \mu \mathrm{g} \mathrm{m}^{-3}$. A standard deviation $(1 \sigma)$ of $2.46 \mu \mathrm{g} \mathrm{m}^{-3}(14 \%)$ was calculated between chemically reconstructed $\mathrm{PM}_{1}$ from Q-ACSM and TEOM-FDMS. These results are consistent with a 2-year study performed at SIRTA by Petit et al. (2015), for which a slope of $1.06\left(r^{2}=0.85\right)$ was found between daily averaged TEOM-FDMS PM 1 and Q-ACSM combined with Aethalometer measurements. Sun et al. (2012) reported a lower correlation between those instruments $\left(r^{2}=0.68\right.$; slope $\left.=0.64\right)$ that might be explained by the use of a $\mathrm{PM}_{2.5}$ size cut-off mounted upstream the TEOM-FDMS and an important $\mathrm{PM}_{1-2.5}$ fraction in Beijing not measured by the Q-ACSM. The best correlation with $\mathrm{PM}_{1}$ from Q-ACSM was found to be with the ToFACSM data $\left(r^{2}=0.88\right.$; slope $\left.=0.91\right)$. The comparison with the HR-ToF-AMS showed a slope close to one but correlated slightly less well $\left(r^{2}=0.78\right.$; slope $\left.=0.99\right)$. When the intercept is forced through zero, the agreement is better between Q-ACSM and ToF-ACSM with a slope closer to one $\left(r^{2}=0.88\right.$, slope $\left.=0.96\right)$, but lower between Q-ACSM and HR-ToF-AMS $\left(r^{2}=0.76\right.$, slope $\left.=1.13\right)$. The indirect comparison with optically derived $\mathrm{PM}_{1}$ from light scattering coefficient yielded to rather satisfactory results $\left(r^{2}=0.80\right.$, slope of 1.05 with an intercept of $3.87 \mu \mathrm{g} \mathrm{m}^{-3} ; r^{2}=0.76$, slope of 1.25 with an intercept forced to zero) and a standard deviation of $2.73 \mu \mathrm{g} \mathrm{m}^{-3}(17 \%)$. A good agreement was also observed between nephelometer and median Q-ACSM measurements when reconstructing the light scattering coefficients from online aerosol chemistry data, as detailed in the Supplement (Sect. S6). Finally, comparison with SMPS data appears to be less satisfactory with a slope of 1.32 and a mean standard deviation of $2.44 \mu \mathrm{g} \mathrm{m}^{-3}(18 \%)$, although the determination coefficient $\left(r^{2}\right)$ still remains very good $(0.84)$. This result remains unclear for us and does not improve when a temporal dependence of the density is applied to the SMPS data. It might be hypothesized that the Q-ACSMs used here (or at least some of them) exhibit a lens cut-off slightly above $1 \mu \mathrm{m}$, but this assumption still needs to be checked (e.g., within future intercomparisons). 
(a)

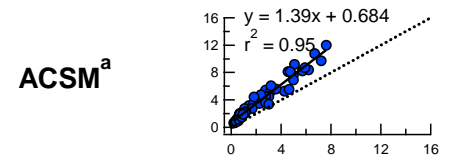

PILS-IC

$\mathrm{NO}_{3}$
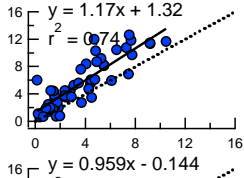

${ }_{12}^{16}-r^{y}=0.959 x$

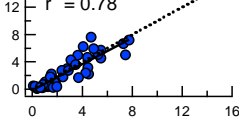

Filters $^{\mathrm{b}}$
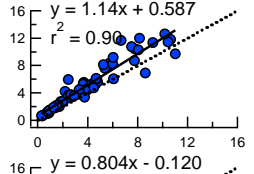

${ }_{16}^{16} E$
${ }_{12} r^{2}=0.804 x$

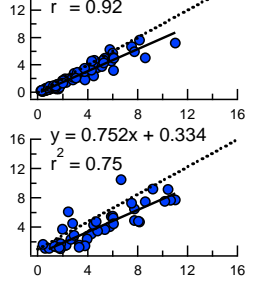

HR-TOF-AMS $^{\text {a }}$
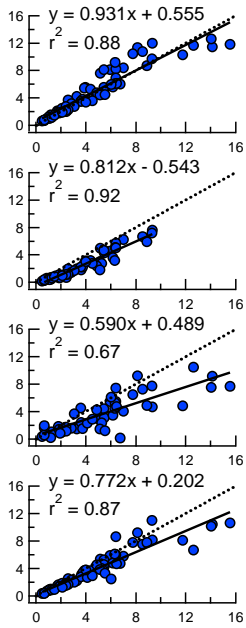

ToF-ACSM $^{\mathrm{a}}$

(b)
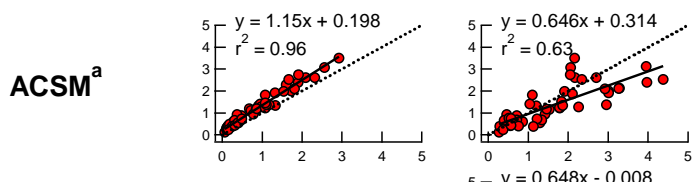

PILS-IC

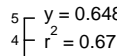

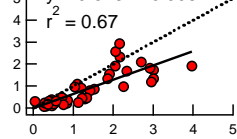

Filters $^{b}$

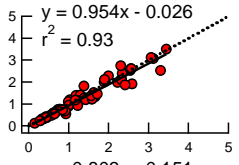

$5-y=0.803 x-1$
$4-r^{2}=0.92$

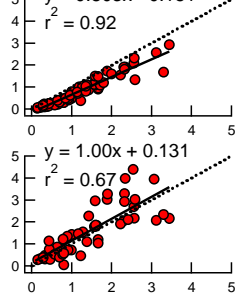

HR-ToF-AMS ${ }^{\mathrm{a}}$

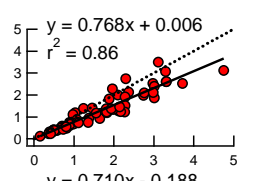

${ }_{4}^{5} F^{y}=0.710 x-0.188$
$r^{2}=0.87$
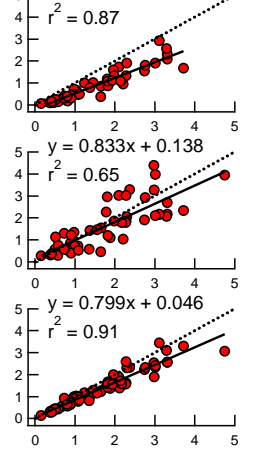

ToF-ACSM $^{\mathrm{a}}$

a: $\mathrm{IE}_{\mathrm{NO} 3}$ calibration dependent, $\mathrm{RIE}_{\mathrm{NH} 4}$ measured, constant $\mathrm{RIE}_{\mathrm{SO} 4}$ of 1.2 and time-dependent collection efficiency (CE) described by Middlebrook et al. (2012) were used to calculate mass concentrations; ${ }^{\mathrm{b}}: \mathrm{PM}_{2.5}$ measurements.

Figure 11.

As a conclusion, the rather good agreement observed between all the instruments providing (in)direct $\mathrm{PM}_{1}$ measurements shows a good consistency of Q-ACSM measurements with external data sets, reinforcing the confidence in the former data set. However, compensating errors may occur and lead to apparent good accuracy when focusing only on NR$\mathrm{PM}_{1}$ Q-ACSM data. For that reason, intercomparison was also performed with each individual chemical constituent and is presented below.

\subsubsection{Q-ACSM chemical components}

Comparisons between Q-ACSM measurements and other online (PILS-IC and OCEC Sunset Field instr.) and off-line (filter sampling) techniques were also performed directly for non-refractory three inorganic components (i.e., $\mathrm{NO}_{3}, \mathrm{SO}_{4}$, $\mathrm{NH}_{4}$; Fig. 11) and indirectly for organics using organic carbon measurements (Fig. 12). 
(c) $\operatorname{ACSM}^{\mathrm{a}}$

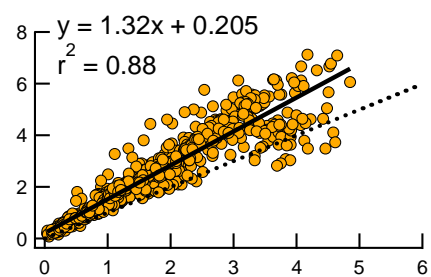

HR-ToF-AMS ${ }^{\mathrm{a}}$
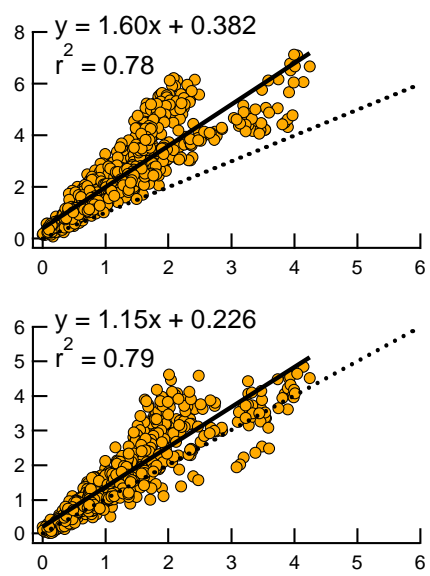

$\mathrm{NH}_{4}$

ToF-ACSM $^{\mathrm{a}}$

Figure 11. Scatter plots of (a) $\mathrm{NO}_{3}$, (b) $\mathrm{SO}_{4}$, and (c) $\mathrm{NH}_{4}$ mass concentrations in $\mu \mathrm{g} \mathrm{m}^{-3}$ measured by Q-ACSM and co-located instruments $(N=97)$. Filter and PILS-IC measurements have not been conducted for ammonium. Data were $6 \mathrm{~h}$ averaged to match filter sampling time for direct intercomparison or $3 \mathrm{~h}$ averaged when filter analyses were not performed. Black solid and dotted lines represent the orthogonal distance regression fits with non-zero intercept and the $1: 1$ lines, respectively. ${ }^{a} \mathrm{IE}_{\mathrm{NO}_{3}}$ calibration dependent, $\mathrm{RIE}_{\mathrm{NH}_{4}}$ measured, constant RIE $\mathrm{SO}_{4}$ of 1.2 and time-dependent collection efficiency (CE) described by Middlebrook et al. (2012) were used to calculate mass concentrations; ${ }^{b}$ $\mathrm{PM}_{2.5}$ measurements.

\section{Sulfate}

The accuracy of sulfate measurements using aerosol mass spectrometers is a subject of current investigation within the scientific community. While rather large discrepancies have been reported in previous studies when comparing Q-ACSM (Ng et al., 2011a; Budisulistiorini et al., 2014) and AMS measurements (Takegawa et al., 2005) to other methodologies, satisfactory agreements have been obtained between QACSM and filter-based measurements at other places (e.g., Ripoll et al., 2015; Minguillon et al., 2015). It is interesting to note here that the $\mathrm{SO}_{4}$ concentrations obtained with PILS-IC are strongly correlated with Q-ACSM median, HRToF-AMS, and ToF-ACSM data $\left(r^{2}=0.96,0.92\right.$, and 0.87; slope $=1.15,0.95$, and 0.77 , respectively) and to a lesser extent with filter measurements $\left(r^{2}=0.63\right.$; slope $\left.=0.65\right)$. A standard averaged deviation $(1 \sigma)$ of $0.23 \mu \mathrm{g} \mathrm{m}^{-3}(23 \%)$ was calculated between $\mathrm{SO}_{4}$ in chemically reconstructed $\mathrm{PM}_{1}$ from Q-ACSM and PILS-IC. These values are close to those given by Fröhlich et al. (2013), Ng et al. (2011a) and Petit et al. (2015).

Sulfate aerosols in the region of Paris typically originate from long-range transport (Sciare et al., 2010; Freutel et al., 2013b; Bressi et al., 2014; Petit et al., 2015) and show a large mode that can extend well above $1 \mu \mathrm{m}$ in diameter (Plaza et al., 2011). This pattern may also contribute to the overestimation of sulfate in $\mathrm{PM}_{2.5}$ filter sampling compared to on-line $\mathrm{PM}_{1}$ techniques. Last but not least, differences may also be attributed to the uncertainties linked to the choice of a unique default $\mathrm{RIESO}_{4}$ and the propagation of subsequent errors into the median Q-ACSM sulfate measurements.

\section{Nitrate}

Similarly, the accuracy of $\mathrm{NO}_{3}$ measurements was also checked by comparing results obtained from the PILS-IC, Q-ACSM, HR-ToF-AMS, ToF-ACSM, and filter sampling. Comparison between the different mass spectrometer techniques leads to very satisfactory results with determination coefficients ranging from 0.88 to 0.90 and slopes ranging from 0.93 to 1.14 (intercepts below $1 \mu \mathrm{g} \mathrm{m}^{-3}$ ). This is supported by the results obtained by $\mathrm{Ng}$ et al. (2011a) who reported a slope close to one $\left(1.01 ; r^{2}=0.88\right)$ between both Q-ACSM and HR-ToF-AMS instruments. Furthermore, our results are in excellent agreement with a previous comparison study between ToF-ACSM vs. Q-ACSM $\left(r^{2}=0.94\right.$; slope $=0.95$; Fröhlich et al., 2013).

Comparison between PILS-IC and the filter technique also leads to very satisfactory results (slope of $0.96 ; r^{2}=0.78$ ). However, discrepancies between Q-ACSM and filter sampling $\left(y=1.17 x+1.32 ; r^{2}=0.74\right)$ as well as between QACSM and PILS-IC $(y=1.39 x+0.68)$ were significant. By contrast, a very satisfactory correlation coefficient $\left(r^{2}=\right.$ $0.95)$ was obtained for the two latter devices. These results are not yet well understood, but could partly be due to uncertainties linked to calibration of the PILS-IC as well as to neg- 


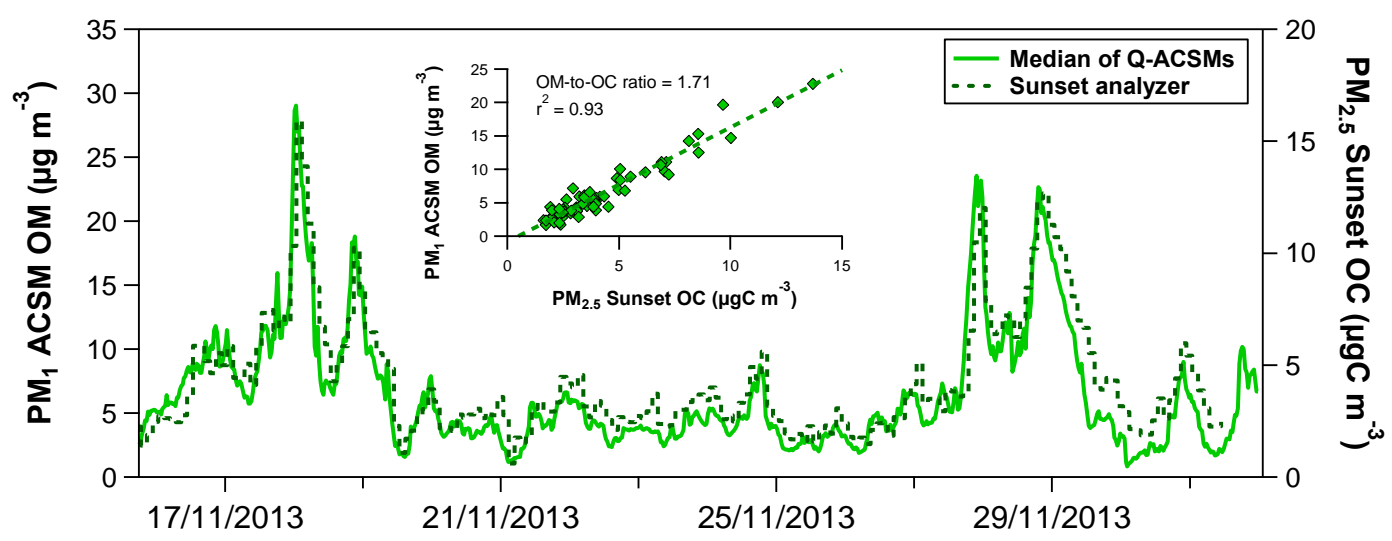

Figure 12. Time series of Q-ACSM OM (median of the 13 Q-ACSMs in light green lines) and Sunset OC mass concentrations (dark green dotted lines) in $\mu \mathrm{g} \mathrm{m}^{-3}$ and corresponding correlation plots. Data are $6 \mathrm{~h}$ averaged to match filter sampling time.

ative artifacts inherent to filter-based measurement of semivolatile species such as ammonium nitrate. As hypothesized previously, lens transmission efficiencies of the Q-ACSMs (and ToF-ACSM) were not investigated in this study and could eventually contribute to these discrepancies.

\section{Ammonium}

Ammonium measurements were not performed by PILS-IC and filter sampling. Both ACSMs and HR-ToF-AMS $\mathrm{NH}_{4}$ measurements are also intrinsically related to nitrate and sulfate measurements, being the major contributor to the neutralization of these two anions. Comparison was then restricted to the three mass spectrometer techniques. Although a good correlation was also observed for $\mathrm{NH}_{4}$ measurements between HR-ToF-AMS, ToF-ACSM and Q-ACSM techniques, with $r^{2}$ above 0.78 , rather large differences were observed (slopes of 1.32 and 1.60) which may partly reflect the high uncertainty in $\mathrm{RIE}_{\mathrm{NH}_{4}}$ determination, propagating biases to the ambient data at high mass concentrations, as reported by Fröhlich et al. (2013).

\section{Organic matter}

The accuracy of Q-ACSM OM measurements was evaluated indirectly with co-located semi-continuous OCEC Sunset Lab instruments. The linear regression between Q-ACSM OM measurements and OC determined from ECOC Sunset field measurements showed an OM-to-OC ratio of $1.71\left(r^{2}=\right.$ 0.93). This is in good agreement with the values reported in the literature for typical urban areas $(1.6 \pm 0.2$, Turpin and Lim, 2001) and very close to the $1.6-1.7$ values obtained in previous studies in the Paris metropolitan area (e.g., Sciare et al., 2010; Crippa et al., 2013c). Furthermore, the OM-to-OC ratio retrieved from the HR-ToF-AMS data set was of 1.77 on average during the study. These results are in agreement with the conclusions of Crippa et al. (2013c) who observed, from HR-ToF-AMS measurements at the SIRTA station, a higher OM-to-OC ratio during the continental-influenced period (1.72), similar to the conditions predominantly occurring during the present study, rather than when Atlantic clean air masses reached the site (1.62). On the other hand, the obtained value of 1.71 is lower than the value of 1.95 determined from $\mathrm{PM}_{2.5}$ filter sampling from 1-year continuous observations in the region of Paris (Bressi et al., 2013). Nevertheless, using a simple assumption that $10 \%$ of OC in $\mathrm{PM}_{2.5}$ is located between 1 and $2.5 \mu \mathrm{m}$ (Ramgolam et al., 2009), the $\mathrm{PM}_{2.5}$ OM-to-OC ratio that could be determined here would rise up to about 1.9 . The very satisfactory comparison between online Q-ACSM and OCEC Sunset field analyzer thus reinforces the ability of the former instrument to accurately estimate OM concentrations. It is also to note that recent studies observed significant seasonal variations of the OM-to-OC ratio, with values up to about 4 during summer (Budisulistiorini et al., 2014), suggesting that the ACSM organic RIE may actually not be constant over time. Future works are still needed to better understand this specific issue. In order to cover different ambient air conditions, a focus will notably be given on organics during the 2nd ACTRIS ACSM intercomparison study at ACMCC, which will take place early spring 2016 , a period of the year generally experiencing high levels of long range transported PM.

\section{Conclusions and recommendations}

This study presents the first-ever ACSM (Aerosol Chemical Speciation Monitor) intercomparison study within the European ACTRIS program. Measurements were performed over a 2-week period at the French SIRTA supersite in the region of Paris during the late fall - early winter period (NovemberDecember 2013). Atmospheric mass concentrations measured by 13 Q-ACSMs were investigated as well as their correlations with various co-located instruments including other aerosol mass spectrometers such as a ToF-ACSM and a HRToF-AMS. Results showed a good agreement for the whole measurements with $r^{2}$ above 0.9 , except for chlorides. The 
Q-ACSM reproducibility was assessed by using a statistical approach that allowed for the determination of Q-ACSM reproducibility uncertainties for NR-PM $\mathrm{P}_{1}$ and their major components $(9,15,19,28$ and $36 \%$ for NR-PM 1 , nitrate, organic matter, sulfate and ammonium respectively). Q-ACSM accuracy was also validated by comparison with various colocated instruments deployed in parallel to the ACSM intercomparison exercise. The $\mathrm{PM}_{1}$ chemical and optical mass closures were achieved as well. The mass concentrations of each chemical constituent retrieved from the Q-ACSM were cross-validated, highlighting the consistency of the correction factors applied to Q-ACSM data sets to calculate mass concentrations and the methodology used for calibrations. Nevertheless, some calibration issues are also reported. Thus, it appears relevant to recommend regular checking of the consistency of the $\mathrm{IE}_{\mathrm{NO}_{3}}$ and $\mathrm{RIE}_{\mathrm{NH}_{4}}$ calibrations performed at SIRTA by comparing the obtained results with calibration values determined at the home institution over time. Additionally, it would be interesting for all the intercomparison participants to apply the calibration values obtained at SIRTA to the Q-ACSM data sets measured at their ACTRIS stations and then check how the Q-ACSM mass concentrations are consistent to additional co-located measurements. Thorough investigations of instrument-dependent $\mathrm{RIE}_{\mathrm{SO}_{4}}$ are also highly recommended. Within the different $\mathrm{RF}_{\mathrm{NO}_{3}}$ and RIE calibrations, the use of a complete SMPS system downstream the DMA used to generate ammonium nitrate and ammonium sulfate particles might help to ensure that the size distribution of calibration aerosol is well-known. This type of check should be done if users have a second SMPS. Q-ACSM users also need to follow the stability of the Q-ACSM corrections back to calibration conditions (e.g., via $\mathrm{AB}$ ) as well as the consistency of CE corrections over time to refine the quality of the Q-ACSM measurements by reducing the uncertainties linked to the calibration procedures. It is especially important when data are then available to the scientific community throughout the databases within European programs (e.g., ACTRIS). Discrepancies observed during the present study highlighted the need to conduct additional and regular intercomparison studies, as will be performed within the ACTRIS-2 program (2015-2019). Such exercises also help to establish and improve sound best-practice and data-quality assessment procedures. Finally, results obtained here call for further investigation of Q-ACSM (i) ammonium sulfate calibration procedures, (ii) transmission efficiency of the aerodynamic lens, and (iii) fragmentation patterns, which seem to be instrument-dependent (especially for $f_{44}$ ). The latter point is of prime interest in the frame of the comparison of results obtained from source apportionment studies as well as from OA oxidation state analysis. The latter issues are discussed in more details in Fröhlich et al. (2015).

\section{The Supplement related to this article is available online} at doi:10.5194/amt-8-5063-2015-supplement.
Acknowledgements. This work was conducted in the frame of the ACTRIS program (European Union Seventh Framework Program (FP7/2007-2013), grant agreement no. 262254). The intercomparison campaign and the following data treatment have been conducted in collaboration with the French reference laboratory for air quality monitoring (LCSQA), funded by the French Ministry of environment. We also thank the ACSM user community for many useful discussions on these topics. The authors acknowledge the French Agency of Environment and Energy Management (ADEME grants 1262C0022 and 1262C0039), the CaPPA (Chemical and Physical Properties of the Atmosphere) project (ANR-10-LABX005) funded by the French National Research Agency (ANR) through the PIA (Programme d'Investissement d'Avenir), the EU-20 FEDER CORSiCA, Eurostars E!4825 and KROP, financed by the Slovenian Ministry of Economic Development and Technology, and ChArMEx projects. J. G. Slowik acknowledges support from the Swiss National Science Foundation (SNSF) through the Ambizione program (PZ00P2_131673). V. Crenn gratefully thanks the DIM-R2DS project Council for his postdoctoral grant. J. Ovadnevaite and C. D. O'Dowd acknowledge HEA-PRTLI4 and NUIG's Research Support Fund. CIEMAT contribution has been partially funded by CGL2011-16124-E, CGL2011-27020 actions from the Spanish National R\&D Programme, and AEROCLIMA (Fundacion Ramon Areces, CIVP16A1811). IDAEA CSIC was partially funded by the Spanish Ministry of Economy and Competitiveness and FEDER funds under the PRISMA (CGL2012-39623-C02-1) project.

Edited by: J. Schneider

\section{References}

Allan, J. D., Delia, A. E., Coe, H., Bower, K. N., Alfarra, M. R., Jimenez, J. L., Middlebrook, A. M., Drewnick, F., Onasch, T. B., Canagaratna, M. R., Jayne, J. T., and Worsnop, D. R.: A generalised method for the extraction of chemically resolved mass spectra from Aerodyne aerosol mass spectrometer data, J. Aerosol Sci., 35, 909-922, doi:10.1016/j.jaerosci.2004.02.007, 2004.

Bae, M.-S., Schauer, J. J., DeMinter, J. T., Turner, J. R., Smith, D., and Cary, R. A.: Validation of a sem-continuous instrument for elemental carbon and organic carbon using a therma-optical method, Atmos. Environ. 38, 288-2893, 2004.

Baumgardner, D., Popovicheva, O., Allan, J., Bernardoni, V., Cao, J., Cavalli, F., Cozic, J., Diapouli, E., Eleftheriadis, K., Genberg, P. J., Gonzalez, C., Gysel, M., John, A., Kirchstetter, T. W., Kuhlbusch, T. A. J., Laborde, M., Lack, D., Müller, T., Niessner, R., Petzold, A., Piazzalunga, A., Putaud, J. P., Schwarz, J., Sheridan, P., Subramanian, R., Swietlicki, E., Valli, G., Vecchi, R., and Viana, M.: Soot reference materials for instrument calibration and intercomparisons: a workshop summary with recommendations, Atmos. Meas. Tech., 5, 1869-1887, doi:10.5194/amt-5-1869-2012, 2012.

Beekmann, M., Prévôt, A. S. H., Drewnick, F., Sciare, J., Pandis, S. N., Denier van der Gon, H. A. C., Crippa, M., Freutel, F., Poulain, L., Ghersi, V., Rodriguez, E., Beirle, S., Zotter, P., von der Weiden-Reinmüller, S.-L., Bressi, M., Fountoukis, C., Petetin, H., Szidat, S., Schneider, J., Rosso, A., El Haddad, I., Megari- 
tis, A., Zhang, Q. J., Michoud, V., Slowik, J. G., Moukhtar, S., Kolmonen, P., Stohl, A., Eckhardt, S., Borbon, A., Gros, V., Marchand, N., Jaffrezo, J. L., Schwarzenboeck, A., Colomb, A., Wiedensohler, A., Borrmann, S., Lawrence, M., Baklanov, A., and Baltensperger, U.: In situ, satellite measurement and model evidence on the dominant regional contribution to fine particulate matter levels in the Paris megacity, Atmos. Chem. Phys., 15, 9577-9591, doi:10.5194/acp-15-9577-2015, 2015.

Belis, C. A., Fröhlich, R., Crenn, V., Bressi, M., Pernigotti, D., Favez, O., Riffault, V., Slowik, J. G., Aas, W., Aijälä, M., Alastuey, A., Artiñano, B., Bonnaire, N., Bozzetti, C., Canonaco, F., Carbone, C., Coz, E., Croteau, P. L., Cubison, M. J., EsserGietl, J. K., Green, D. C., Gros, V., Heikkinen, L., Herrmann, H., Jayne, J. T., Lunder, C. R., Minguillón, M. C., Mocnik, G., O’Dowd, C. D., Ovadnevaite, J., Petralia, E., Poulain, L., Priestman, M., Ripoll, A., Sarda-Estève, R., Setyan, A., Wiedensohler, A., Baltensperger, U., Sciare, J. and Prévôt, A. S. H.: ACTRIS ACSM intercomparison - Part 3: source apportionment of the organic fraction from co-located measurements by 12 independent teams, Atmos. Meas. Tech. Discuss., in preparation, 2015.

Bougiatioti, A., Stavroulas, I., Kostenidou, E., Zarmpas, P., Theodosi, C., Kouvarakis, G., Canonaco, F., Prévôt, A. S. H., Nenes, A., Pandis, S. N., and Mihalopoulos, N.: Processing of biomass-burning aerosol in the eastern Mediterranean during summertime, Atmos. Chem. Phys., 14, 4793-4807, doi:10.5194/acp-14-4793-2014, 2014.

Bressi, M., Sciare, J., Ghersi, V., Bonnaire, N., Nicolas, J. B., Petit, J.-E., Moukhtar, S., Rosso, A., Mihalopoulos, N., and Féron, A.: A one-year comprehensive chemical characterisation of fine aerosol $\left(\mathrm{PM}_{2.5}\right)$ at urban, suburban and rural background sites in the region of Paris (France), Atmos. Chem. Phys., 13, 7825-7844, doi:10.5194/acp-13-7825-2013, 2013.

Bressi, M., Sciare, J., Ghersi, V., Mihalopoulos, N., Petit, J.-E., Nicolas, J. B., Moukhtar, S., Rosso, A., Féron, A., Bonnaire, N., Poulakis, E., and Theodosi, C.: Sources and geographical origins of fine aerosols in Paris (France), Atmos. Chem. Phys., 14, 8813-8839, doi:10.5194/acp-14-8813-2014, 2014.

Budisulistiorini, S. H., Canagaratna, M. R., Croteau, P. L., Marth, W. J., Baumann, K., Edgerton, E. S., Shaw, S. L., Knipping, E. L., Worsnop, D. R., Jayne, J. T., Gold, A., and Surratt, J. D.: Real-time continuous characterization of secondary organic aerosol derived from isoprene epoxydiols in downtown Atlanta, Georgia, using the Aerodyne Aerosol Chemical Speciation Monitor, Environ. Sci. Technol., 47, 5686-5694, 2013.

Budisulistiorini, S. H., Canagaratna, M. R., Croteau, P. L., Baumann, K., Edgerton, E. S., Kollman, M. S., Ng, N. L., Verma, V., Shaw, S. L., Knipping, E. M., Worsnop, D. R., Jayne, J. T., Weber, R.J., and Surratt, J. D.: Intercomparison of an Aerosol Chemical Speciation Monitor (ACSM) with ambient fine aerosol measurements in downtown Atlanta, Georgia, Atmos. Meas. Tech., 7, 1929-1941, doi:10.5194/amt-7-1929-2014, 2014.

Budisulistiorini, S. H., Baumann, K., Edgerton, E. S., Bairai, S. T., Mueller, S., Shaw, S. L., Knipping, E. M., Gold, A., and Surratt, J. D.: Seasonal characterization of submicron aerosol chemical composition and organic aerosol sources in the southeastern United States: Atlanta, Georgia and Look Rock, Tennessee, Atmos. Chem. Phys. Discuss., 15, 22379-22417, doi:10.5194/acpd-15-22379-2015, 2015a.
Budisulistiorini, S. H., Li, X., Bairai, S. T., Renfro, J., Liu, Y., Liu, Y. J., McKinney, K. A., Martin, S. T., McNeill, V. F., Pye, H. O. T., Nenes, A., Neff, M. E., Stone, E. A., Mueller, S., Knote, C., Shaw, S. L., Zhang, Z., Gold, A., and Surratt, J. D.: Examining the effects of anthropogenic emissions on isoprenederived secondary organic aerosol formation during the 2013 Southern Oxidant and Aerosol Study (SOAS) at the Look Rock, Tennessee ground site, Atmos. Chem. Phys., 15, 8871-8888, doi:10.5194/acp-15-8871-2015, 2015 b.

Canagaratna, M. R., Jayne, J. T., Jimenez, J. L., Allan, J. D., Alfarra, M. R., Zhang, Q., Onasch, T. B., Drewnick, F., Coe, H., Middlebrook, A., Delia, A., Williams, L. R., Trimborn, A. M., Northway, M. J., DeCarlo, P. F., Kolb, C. E., Davidovits, P., and Worsnop, D. R.: Chemical and microphysical characterization of ambient aerosols with the aerodyne aerosol mass spectrometer, Mass Spectrom. Rev., 26, 185-222, doi:10.1002/mas.20115, 2007.

Canagaratna, M. R., Jimenez, J. L., Kroll, J. H., Chen, Q., Kessler, S. H., Massoli, P., Hildebrandt Ruiz, L., Fortner, E., Williams, L. R., Wilson, K. R., Surratt, J. D., Donahue, N. M., Jayne, J. T., and Worsnop, D. R.: Elemental ratio measurements of organic compounds using aerosol mass spectrometry: characterization, improved calibration, and implications, Atmos. Chem. Phys., 15, 253-272, doi:10.5194/acp-15-253-2015, 2015.

Canonaco, F., Crippa, M., Slowik, J. G., Baltensperger, U., and Prévôt, A. S. H.: SoFi, an IGOR-based interface for the efficient use of the generalized multilinear engine (ME-2) for the source apportionment: ME-2 application to aerosol mass spectrometer data, Atmos. Meas. Tech., 6, 3649-3661, doi:10.5194/amt6-3649-2013, 2013

Carbone, S., Saarikoski, S., Frey, A., Reyes, F., Reyes, P., Castillo, M., Gramsch, E., Oyola, P., Jayne, J. T., Worsnop, D. R., and Hillamo, R.: Chemical characterization of submicron aerosol particles in Santiago de Chile, Aerosol Air Qual. Res., 13, 462473, 2013.

Cavalli, F., Putaud, J. F., and Yttri, K. E.: Availability and Quality of the EC and OC Measurements Within EMEP, Including Results of the Fourth Interlaboratory Comparison of Analytical Methods for Carbonaceous Particulate Matter Within EMEP (2011), EMEP/CCC-Report 1/2013, avialable at: http: //www.nilu.no/projects/ccc/reports/cccr1-2013.pdf, 2013.

Chow, J. C., Watson, J. G., Lowenthal, D. H., and Richards, L. W.: Comparability between $\mathrm{PM}_{2.5}$ and particle light scattering measurements, Environ. Monit. Assess., 79, 29-45, 2002.

Crippa, M., Canonaco, F., Slowik, J. G., El Haddad, I., DeCarlo, P. F., Mohr, C., Heringa, M. F., Chirico, R., Marchand, N., Temime-Roussel, B., Abidi, E., Poulain, L., Wiedensohler, A., Baltensperger, U., and Prévôt, A. S. H.: Primary and secondary organic aerosol origin by combined gas-particle phase source apportionment, Atmos. Chem. Phys., 13, 84118426, doi:10.5194/acp-13-8411-2013, 2013a.

Crippa, M., DeCarlo, P. F., Slowik, J. G., Mohr, C., Heringa, M. F., Chirico, R., Poulain, L., Freutel, F., Sciare, J., Cozic, J., Di Marco, C. F., Elsasser, M., Nicolas, J. B., Marchand, N., Abidi, E., Wiedensohler, A., Drewnick, F., Schneider, J., Borrmann, S., Nemitz, E., Zimmermann, R., Jaffrezo, J.-L., Prévôt, A. S. H., and Baltensperger, U.: Wintertime aerosol chemical composition and source apportionment of the organic 
fraction in the metropolitan area of Paris, Atmos. Chem. Phys., 13, 961-981, doi:10.5194/acp-13-961-2013, 2013b.

Crippa, M., El Haddad, I., Slowik, J. G., DeCarlo, P. F., Mohr, C., Heringa, M. F., Chirico, R., Marchand, N., Sciare, J., Baltensperger, U., and Prévôt, A. S. H.: Identification of marine and continental aerosol sources in Paris using high resolution aerosol mass spectrometry, J. Geophys. Res.-Atmos., 118, 1950-1963, doi:10.1002/jgrd.50151, 2013c.

DeCarlo, P. F., Kimmel, J. R., Trimborn, A., Northway, M. J., Jayne, J. T., Aiken, A. C., Gonin, M., Fuhrer, K., Horvath, T., Docherty, K. S., Worsnop, D. R., and Jimenez, J. L.: Fielddeployable, high-resolution, Time-of-Flight Aerosol Mass Spectrometer, Anal. Chem., 78, 8281-8289, doi:10.1021/ac061249n, 2006.

Drinovec, L., Močnik, G., Zotter, P., Prévôt, A. S. H., Ruckstuhl, C., Coz, E., Rupakheti, M., Sciare, J., Müller, T., Wiedensohler, A., and Hansen, A. D. A.: The "dual-spot" Aethalometer: an improved measurement of aerosol black carbon with realtime loading compensation, Atmos. Meas. Tech., 8, 1965-1979, doi:10.5194/amt-8-1965-2015, 2015.

Duplissy, J., DeCarlo, P. F., Dommen, J., Alfarra, M. R., Metzger, A., Barmpadimos, I., Prevot, A. S. H., Weingartner, E., Tritscher, T., Gysel, M., Aiken, A. C., Jimenez, J. L., Canagaratna, M. R., Worsnop, D. R., Collins, D. R., Tomlinson, J., and Baltensperger, U.: Relating hygroscopicity and composition of organic aerosol particulate matter, Atmos. Chem. Phys., 11, 1155-1165, doi:10.5194/acp-11-1155-2011, 2011.

Forster, P., Ramaswamy, V., Artaxo, P., Berntsen, T., Betts, R., Fahey, D., Haywood, J., Lean, J., Lowe, D., and Myhre, G.: Changes in atmospheric constituents and in radiative forcing, in: Climate Change 2007: The Physical Science Basis, edited by: Solomon, S., available at: http://www.ipcc.ch/pdf/ assessment-report/ar4/wg1/ar4-wg1-chapter2.pdf, 2007.

Freutel, F., Drewnick, F., Schneider, J., Klimach, T., and Borrmann, S.: Quantitative single-particle analysis with the Aerodyne aerosol mass spectrometer: development of a new classification algorithm and its application to field data, Atmos. Meas. Tech., 6, 3131-3145, doi:10.5194/amt-6-3131-2013, $2013 \mathrm{a}$.

Freutel, F., Schneider, J., Drewnick, F., von der WeidenReinmüller, S.-L., Crippa, M., Prévôt, A. S. H., Baltensperger, U., Poulain, L., Wiedensohler, A., Sciare, J., SardaEstève, R., Burkhart, J. F., Eckhardt, S., Stohl, A., Gros, V., Colomb, A., Michoud, V., Doussin, J. F., Borbon, A., Haeffelin, M., Morille, Y., Beekmann, M., and Borrmann, S.: Aerosol particle measurements at three stationary sites in the megacity of Paris during summer 2009: meteorology and air mass origin dominate aerosol particle composition and size distribution, Atmos. Chem. Phys., 13, 933-959, doi:10.5194/acp-13-933-2013, 2013b.

Fröhlich, R., Cubison, M. J., Slowik, J. G., Bukowiecki, N., Prévôt, A. S. H., Baltensperger, U., Schneider, J., Kimmel, J. R., Gonin, M., Rohner, U., Worsnop, D. R., and Jayne, J. T.: The ToF-ACSM: a portable aerosol chemical speciation monitor with TOFMS detection, Atmos. Meas. Tech., 6, 3225-3241, doi:10.5194/amt-6-3225-2013, 2013.

Fröhlich, R., Crenn, V., Setyan, A., Belis, C. A., Canonaco, F., Favez, O., Riffault, V., Slowik, J. G., Aas, W., Aijälä, M., Alastuey, A., Artiñano, B., Bonnaire, N., Bozzetti, C., Bressi, M., Carbone, C., Coz, E., Croteau, P. L., Cubison, M. J., Esser-
Gietl, J. K., Green, D. C., Gros, V., Heikkinen, L., Herrmann, H., Jayne, J. T., Lunder, C. R., Minguillón, M. C., Močnik, G., O'Dowd, C. D., Ovadnevaite, J., Petralia, E., Poulain, L., Priestman, M., Ripoll, A., Sarda-Estève, R., Wiedensohler, A., Baltensperger, U., Sciare, J., and Prévôt, A. S. H.: ACTRIS ACSM intercomparison - Part 2: Intercomparison of ME-2 organic source apportionment results from 15 individual, co-located aerosol mass spectrometers, Atmos. Meas. Tech., 8, 2555-2576, doi:10.5194/amt-8-2555-2015, 2015.

Grover, B. D., Kleinman, M., Eatough, N. L., Eatough, D. J., Hopke, P. K., Long, R. W., Wilson, W. E., Meyer, M. B., and Ambs, J. L.: Measurement of total $\mathrm{PM}_{2.5}$ mass (nonvolatile plus semivolatile) with the Filter Dynamic Measurement System tapered element oscillating microbalance monitor, J. Geophys. Res.-Atmos., 110, D07S03, doi:10.1029/2004JD004995, 2005.

Haeffelin, M., Barthès, L., Bock, O., Boitel, C., Bony, S., Bouniol, D., Chepfer, H., Chiriaco, M., Cuesta, J., Delanoë, J., Drobinski, P., Dufresne, J.-L., Flamant, C., Grall, M., Hodzic, A., Hourdin, F., Lapouge, F., Lemaître, Y., Mathieu, A., Morille, Y., Naud, C., Noël, V., O'Hirok, W., Pelon, J., Pietras, C., Protat, A., Romand, B., Scialom, G., and Vautard, R.: SIRTA, a groundbased atmospheric observatory for cloud and aerosol research, Ann. Geophys., 23, 253-275, doi:10.5194/angeo-23-253-2005, 2005.

Hand, J. L. and Malm, W. C.: Review of aerosol mass scattering efficiencies from ground-based measurements since 1990, J. Geophys. Res.-Atmos., 112, 1984-2012, 2007.

Healy, R. M., Sciare, J., Poulain, L., Crippa, M., Wiedensohler, A., Prévôt, A. S. H., Baltensperger, U., Sarda-Estève, R., McGuire, M. L., Jeong, C.-H., McGillicuddy, E., O’Connor, I. P., Sodeau, J. R., Evans, G. J., and Wenger, J. C.: Quantitative determination of carbonaceous particle mixing state in Paris using single-particle mass spectrometer and aerosol mass spectrometer measurements, Atmos. Chem. Phys., 13, 9479-9496, doi:10.5194/acp-13-9479-2013, 2013.

ISO/IEC 17025: General Requirements for the Competence of Testing and Calibration Laboratories, International Organization for Standardization, Geneva, 1999.

ISO, 5725-2: Accuracy (Trueness and Precision) of Measurement Methods and Results - Part 2: Basic Method for the Determination of Repeatability and Reproducibility of a Standard Measurement Method, International Organization for Standardization, Geneva, 1994.

ISO, 5725-5: Accuracy (Trueness and Precision) of Measurement Methods and Results - Part 5: Alternative Methods for the Determination of the Precision of a Standard Measurement Method, International Organization for Standardization, Geneva, 1998.

ISO, 13528: Statistical Methods for Use in Proficiency Testing by Interlaboratory Comparison, International Organization for Standardization, Geneva, 2005.

Jayne, J. T., Leard, D. C., Zhang, X., Davidovits, P., Smith, K. A., Kolb, C. E., and Worsnop, D. R.: Development of an Aerosol Mass Spectrometer for Size and Composition Analysis of Submicron Particles, Aerosol Sci. Tech. 33, 49-70, doi:10.1080/027868200410840, 2000.

Jiang, Q., Sun, Y. L., Wang, Z., and Yin, Y.: Aerosol composition and sources during the Chinese Spring Festival: fireworks, secondary aerosol, and holiday effects, Atmos. Chem. Phys., 15, 6023-6034, doi:10.5194/acp-15-6023-2015, 2015. 
Kroll, J. H., Donahue, N. M., Jimenez, J. L., Kessler, S. H., Canagaratna, M. R., Wilson, K. R., Altieri, K. E., Mazzoleni, L. R., Wozniak, A. S., Bluhm, H., Mysak, E. R., Smith, J. D., Kolb, C. E., and Worsnop, D. R.: Carbon oxidation state as a metric for describing the chemistry of atmospheric organic aerosol, Nat. Chem. 3, 133-139, doi:10.1038/nchem.948, 2011.

Kroll, J. H., Cross, E. S., Hunter, J. F., Pai, S., Wallace, L. M., Croteau, P. L., Jayne, J. T., Worsnop, D. R., Heald, C. L., Murphy, J. G., and Frankel, S. L.: Atmospheric evolution of sulfur emissions from Kīlauea: real-time measurements of oxidation, dilution, and neutralization within a volcanic plume, Environ. Sci. Technol., 49, 4129-4137, 2015.

Laborde, M., Schnaiter, M., Linke, C., Saathoff, H., Naumann, K.H., Möhler, O., Berlenz, S., Wagner, U., Taylor, J. W., Liu, D., Flynn, M., Allan, J. D., Coe, H., Heimerl, K., Dahlkötter, F., Weinzierl, B., Wollny, A. G., Zanatta, M., Cozic, J., Laj, P., Hitzenberger, R., Schwarz, J. P., and Gysel, M.: Single Particle Soot Photometer intercomparison at the AIDA chamber, Atmos. Meas. Tech., 5, 3077-3097, doi:10.5194/amt-5-3077-2012, 2012.

Liu, P. S., Deng, R., Smith, K. A., Williams, L. R., Jayne, J. T., Canagaratna, M. R., Moore, K., Onasch, T. B., Worsnop, D. R., and Deshler, T.: Transmission efficiency of an aerodynamic focusing lens system: comparison of model calculations and laboratory measurements for the Aerodyne Aerosol Mass Spectrometer, Aerosol Sci. Tech., 41, 721-733, 2007.

Middlebrook, A. M., Bahreini, R., Jimenez, J. L., and Canagaratna, M. R.: Evaluation of composition-dependent collection efficiencies for the Aerodyne Aerosol Mass Spectrometer using field data, Aerosol Sci. Tech., 46, 258-271, doi:10.1080/02786826.2011.620041, 2012.

Minguillón, M. C., Ripoll, A., Pérez, N., Prévôt, A. S. H., Canonaco, F., Querol, X., and Alastuey, A.: Chemical characterization of submicron regional background aerosols in the western Mediterranean using an Aerosol Chemical Speciation Monitor, Atmos. Chem. Phys., 15, 6379-6391, doi:10.5194/acp-15-63792015, 2015.

Ng, N. L., Canagaratna, M. R., Zhang, Q., Jimenez, J. L., Tian, J., Ulbrich, I. M., Kroll, J. H., Docherty, K. S., Chhabra, P. S., Bahreini, R., Murphy, S. M., Seinfeld, J. H., Hildebrandt, L., Donahue, N. M., DeCarlo, P. F., Lanz, V. A., Prévôt, A. S. H., Dinar, E., Rudich, Y., and Worsnop, D. R.: Organic aerosol components observed in Northern Hemispheric datasets from Aerosol Mass Spectrometry, Atmos. Chem. Phys., 10, 46254641, doi:10.5194/acp-10-4625-2010, 2010.

Ng, N. L., Herndon, S. C., Trimborn, A., Canagaratna, M. R., Croteau, P. L., Onasch, T. B., Sueper, D., Worsnop, D. R., Zhang, Q., Sun, Y. L., and Jayne, J. T.: An aerosol chemical speciation monitor (ACSM) for routine monitoring of the composition and mass concentrations of ambient aerosol, Aerosol Sci. Tech., 45, 780-794, doi:10.1080/02786826.2011.560211, 2011a.

Ng, N. L., Canagaratna, M. R., Jimenez, J. L., Chhabra, P. S., Seinfeld, J. H., and Worsnop, D. R.: Changes in organic aerosol composition with aging inferred from aerosol mass spectra, Atmos. Chem. Phys., 11, 6465-6474, doi:10.5194/acp-11-64652011, 2011b.

Orsini, D. A., Ma, Y., Sullivan, A., Sierau, B., Baumann, K., and Weber, R. J.: Refinements to the particle-into-liquid sampler (PILS) for ground and airborne measurements of water soluble aerosol composition, Atmos. Environ. 37, 1243-1259, doi:10.1016/S1352-2310(02)01015-4, 2003.

Panteliadis, P., Hafkenscheid, T., Cary, B., Diapouli, E., Fischer, A., Favez, O., Quincey, P., Viana, M., Hitzenberger, R., Vecchi, R., Saraga, D., Sciare, J., Jaffrezo, J. L., John, A., Schwarz, J., Giannoni, M., Novak, J., Karanasiou, A., Fermo, P., and Maenhaut, W.: ECOC comparison exercise with identical thermal protocols after temperature offset correction - instrument diagnostics by in-depth evaluation of operational parameters, Atmos. Meas. Tech., 8, 779-792, doi:10.5194/amt-8-779-2015, 2015.

Parworth, C., Fast, J., Mei, F., Shippert, T., Sivaraman, C., Tilp, A., Watson, T., and Zhang, Q.: Long-term measurements of submicrometer aerosol chemistry at the Southern Great Plains (SGP) using an Aerosol Chemical Speciation Monitor (ACSM), Atmos. Environ. 106, 43-55, 2015.

Petit, J.-E., Favez, O., Sciare, J., Canonaco, F., Croteau, P., Močnik, G., Jayne, J., Worsnop, D., and Leoz-Garziandia, E.: Submicron aerosol source apportionment of wintertime pollution in Paris, France by double positive matrix factorization $\left(\mathrm{PMF}^{2}\right)$ using an aerosol chemical speciation monitor (ACSM) and a multi-wavelength Aethalometer, Atmos. Chem. Phys., 14, 13773-13787, doi:10.5194/acp-14-13773-2014, 2014.

Petit, J.-E., Favez, O., Sciare, J., Crenn, V., Sarda-Estève, R., Bonnaire, N., Močnik, G., Dupont, J.-C., Haeffelin, M., and LeozGarziandia, E.: Two years of near real-time chemical composition of submicron aerosols in the region of Paris using an Aerosol Chemical Speciation Monitor (ACSM) and a multiwavelength Aethalometer, Atmos. Chem. Phys., 15, 2985-3005, doi:10.5194/acp-15-2985-2015, 2015.

Petzold, A., Onasch, T., Kebabian, P., and Freedman, A.: Intercomparison of a Cavity Attenuated Phase Shift-based extinction monitor (CAPS PMex) with an integrating nephelometer and a filterbased absorption monitor, Atmos. Meas. Tech., 6, 1141-1151, doi:10.5194/amt-6-1141-2013, 2013.

Plaza, J., Pujadas, M., Gómez-Moreno, F. J., Sánchez, M., and Artíñano, B.: Mass size distributions of soluble sulfate, nitrate and ammonium in the Madrid urban aerosol, Atmos. Environ. 45, 4966-4976, 2011.

Ramgolam, K., Favez, O., Cachier, H., Gaudichet, A., Marano, F., Martinon, L., and Baeza-Squiban, A.: Size-partitioning of an urban aerosol to identify particle determinants involved in the proinflammatory response induced in airway epithelial cells, Part. Fibre Toxicol., 6:10, doi:10.1186/1743-8977-6-10, 2009.

Ripoll, A., Minguillón, M. C., Pey, J., Jimenez, J. L., Day, D. A., Sosedova, Y., Canonaco, F., Prévôt, A. S. H., Querol, X., and Alastuey, A.: Long-term real-time chemical characterization of submicron aerosols at Montsec (southern Pyrenees, $1570 \mathrm{~m}$ a.s.1.), Atmos. Chem. Phys., 15, 2935-2951, doi:10.5194/acp-152935-2015, 2015.

Sciare, J., Sarda-Estève, R., Favez, O., Cachier, H., Aymoz, G., and Laj, P.: Nighttime residential wood burning evidenced from an indirect method for estimating real-time concentration of particulate organic matter (POM), Atmos. Environ. 42, 2158-2172, doi:10.1016/j.atmosenv.2007.11.053, 2008.

Sciare, J., d'Argouges, O., Zhang, Q. J., Sarda-Estève, R., Gaimoz, C., Gros, V., Beekmann, M., and Sanchez, O.: Comparison between simulated and observed chemical composition of fine aerosols in Paris (France) during springtime: contribution 
of regional versus continental emissions, Atmos. Chem. Phys., 10, 11987-12004, doi:10.5194/acp-10-11987-2010, 2010.

Sciare, J., d' Argouges, O., Sarda-Estève, R., Gaimoz, C., Dolgorouky, C., Bonnaire, N., Favez, O., Bonsang, B., and Gros, V.: Large contribution of water-insoluble secondary organic aerosols in the region of Paris (France) during wintertime, J. Geophys. Res.-Atmos., 116, D22203, doi:10.1029/2011JD015756, 2011.

Sun, Y., Wang, Z., Dong, H., Yang, T., Li, J., Pan, X., Chen, P., and Jayne, J. T.: Characterization of summer organic and inorganic aerosols in Beijing, China with an Aerosol Chemical Speciation Monitor, Atmos. Environ. 51, 250-259, doi:10.1016/j.atmosenv.2012.01.013, 2012.

Takahama, S., Johnson, A., Guzman Morales, J., Russell, L. M., Duran, R., Rodriguez, G., Zheng, J., Zhang, R., Toom-Sauntry, D., and Leaitch, W. R.: Submicron organic aerosol in Tijuana, Mexico, from local and Southern California sources during the CalMex campaign, Atmos. Environ. 70, 500-512, doi:10.1016/j.atmosenv.2012.07.057, 2013.

Thompson, M., Ellison, S. L. R., and Wood, R.: The international harmonized protocol for the proficiency testing of analytical chemistry laboratories, IUPAC Technical Report, Pure Appl. Chem., 78, 145-196, 2006.

Titos, G., Foyo-Moreno, I., Lyamani, H., Querol, X., Alastuey, A., and Alados-Arboledas, L.: Optical properties and chemical composition of aerosol particles at an urban location: an estimation of the aerosol mass scattering and absorption efficiencies, J. Geophys. Res.-Atmos., 117, 1984-2012, 2012.

Takegawa, N., Miyazaki, Y., Kondo, Y., Komazaki, Y., Miyakawa, T., Jimenez, J. L., Jayne, J. T., Worsnop, D. R., Allan, J. D., and Weber, R. J.: Characterization of an Aerodyne Aerosol Mass Spectrometer (AMS): intercomparison with other aerosol instruments, Aerosol Sci. Tech. 39, 760-770, doi:10.1080/02786820500243404, 2005.

von der Weiden-Reinmüller, S.-L., Drewnick, F., Crippa, M., Prévôt, A. S. H., Meleux, F., Baltensperger, U., Beekmann, M., and Borrmann, S.: Application of mobile aerosol and trace gas measurements for the investigation of megacity air pollution emissions: the Paris metropolitan area, Atmos. Meas. Tech., 7, 279-299, doi:10.5194/amt-7-279-2014, 2014.

Wiedensohler, A., Birmili, W., Nowak, A., Sonntag, A., Weinhold, K., Merkel, M., Wehner, B., Tuch, T., Pfeifer, S., Fiebig, M., Fjäraa, A. M., Asmi, E., Sellegri, K., Depuy, R., Venzac, H., Villani, P., Laj, P., Aalto, P., Ogren, J. A., Swietlicki, E., Williams, P., Roldin, P., Quincey, P., Hüglin, C., FierzSchmidhauser, R., Gysel, M., Weingartner, E., Riccobono, F., Santos, S., Grüning, C., Faloon, K., Beddows, D., Harrison, R., Monahan, C., Jennings, S. G., O'Dowd, C. D., Marinoni, A., Horn, H.-G., Keck, L., Jiang, J., Scheckman, J., McMurry, P. H., Deng, Z., Zhao, C. S., Moerman, M., Henzing, B., de Leeuw, G., Löschau, G., and Bastian, S.: Mobility particle size spectrometers: harmonization of technical standards and data structure to facilitate high quality long-term observations of atmospheric particle number size distributions, Atmos. Meas. Tech., 5, 657-685, doi:10.5194/amt-5-657-2012, 2012.
World Health Organization (WHO): World health statistics 2012: noncommunicable diseases: a major health challenge of the $21 \mathrm{st}$ century, Geneva: World Health Organization, 2012.

Yttri, K. E., Schnelle-Kreis, J., Maenhaut, W., Abbaszade, G., Alves, C., Bjerke, A., Bonnier, N., Bossi, R., Claeys, M., Dye, C., Evtyugina, M., García-Gacio, D., Hillamo, R., Hoffer, A., Hyder, M., Iinuma, Y., Jaffrezo, J.-L., Kasper-Giebl, A., Kiss, G., López-Mahia, P. L., Pio, C., Piot, C., Ramirez-Santa-Cruz, C., Sciare, J., Teinilä, K., Vermeylen, R., Vicente, A., and Zimmermann, R.: An intercomparison study of analytical methods used for quantification of levoglucosan in ambient aerosol filter samples, Atmos. Meas. Tech., 8, 125-147, doi:10.5194/amt-8-1252015, 2015.

Zhang, Q. J., Beekmann, M., Drewnick, F., Freutel, F., Schneider, J., Crippa, M., Prevot, A. S. H., Baltensperger, U., Poulain, L., Wiedensohler, A., Sciare, J., Gros, V., Borbon, A., Colomb, A., Michoud, V., Doussin, J.-F., Denier van der Gon, H. A. C., Haeffelin, M., Dupont, J.-C., Siour, G., Petetin, H., Bessagnet, B., Pandis, S. N., Hodzic, A., Sanchez, O., Honoré, C., and Perrussel, O.: Formation of organic aerosol in the Paris region during the MEGAPOLI summer campaign: evaluation of the volatilitybasis-set approach within the CHIMERE model, Atmos. Chem. Phys., 13, 5767-5790, doi:10.5194/acp-13-5767-2013, 2013.

Zhang, Y. J., Tang, L. L., Wang, Z., Yu, H. X., Sun, Y. L., Liu, D., Qin, W., Canonaco, F., Prévôt, A. S. H., Zhang, H. L., and Zhou, H. C.: Insights into characteristics, sources, and evolution of submicron aerosols during harvest seasons in the Yangtze River delta region, China, Atmos. Chem. Phys., 15, 1331-1349, doi:10.5194/acp-15-1331-2015, 2015. 